\title{
Accurate Direct PCR with Arabidopsis and rice
}

\author{
Authors: Peter Lynagh ${ }^{1,2}$, Kansinee Hungsaprug ${ }^{1}$, Paul Osuna-Kleist ${ }^{1}$, Edgar Malagon ${ }^{1}$ \\ Ek Han $\operatorname{Tan}^{1,3}$, and Luca Comai ${ }^{\star 1,2}$ \\ Department of Plant Biology and Genome Center, Davis, CA, USA ${ }^{1}$ \\ Innovative Genomics Institute, University of California, Berkeley, CA, USA ${ }^{2}$ \\ Current Address: School of Biology and Ecology, University of Maine, Orono, Maine ${ }^{3}$ \\ *Corresponding Author: Luca Comai, Icomai@ucdavis.edu
}

\section{Abstract}

Methods for PCR that avoid costly and time consuming plant DNA purification have not been widely adopted, partly because their efficacy is unclear. Here, we compare different sampling methods for Direct PCR in Arabidopsis and rice. CutTip, stabbing a pipette tip into a plant organ and depositing the tip of the pipette tip into the reaction buffer, yielded high accuracy for genotyping and detection of CRISPR-induced mutations. This did not require visible tissue fragments in the reactions. We demonstrate the usefulness of this method in sampling many locations within a single plant to identify a rare CRISPR-mutated sector. These methods are simple, inexpensive and can help address the challenge of genotyping and genome editing at different scales with high accuracy. The methods also simplify the application of PCR in the field. 


\section{Introduction}

Polymerase Chain Reaction (PCR) continues to be one of the most powerful tools in molecular biology. However, PCR can frequently fail if starting with too few DNA molecules or impure DNA. Plant biologists tend to assume that plant DNA needs to go through at least a rudimentary DNA purification process in order for PCR to have the desired success, i.e. high accuracy. Accuracy is defined by the combination of high sensitivity and high specificity, i.e. by low false negatives and low false positives. However, DNA purification can be expensive in regards to money, time and effort. The most popular DNA purification method entails high speed centrifugation steps in chemicals such as chloroform and isopropanol followed by drying and dissolution of the DNA (Fig. 1A, 1B).

The DNA purification steps can be minimized or eliminated. Direct PCR is defined as PCR that does not include any DNA purification step in the protocol (Fig. 1C). The strict definition of Direct PCR used in this article includes only methods in which (certainly impure) DNA is directly transferred from the plant to the PCR reagents. Thus, Direct PCR can be relatively inexpensive, fast and easy. Though not commonly used, Direct PCR has been shown to work in many plant species. Amplification by Direct PCR has been demonstrated in dozens of diverse plant species including liverworts, mosses, ferns, monocots and dicots 1234567 .

Although plant Direct PCR clearly can work, one reason that plant Direct PCR has not become popular is that plant tissue can strongly inhibit PCR ${ }^{2}$. Tissue pieces as small as $1 \mathrm{~mm}^{2}$ are inhibitory in some species ${ }^{6}$. Specialized plant Direct PCR buffers that lessen inhibition are commercially available, but we wondered if there might be a simpler way to achieve high plant Direct PCR accuracy.

One of the simplest Direct PCR methods is to use a scalpel or tweezers to pick a roughly $1 \mathrm{~mm}^{2}$ piece of tissue and put it directly in the PCR reagents ${ }^{8}$. It requires an attentive technician if tissue $>1 \mathrm{~mm}^{2}$ inhibits the reaction. One of the first and simplest plant Direct PCR methods described involves poking a leaf with a pipette tip, then pipetting the visible tissue directly into the PCR reagents ${ }^{1}$, which we call the Berthomieu-Meyer (B.M.) method. The study noted that some of the reactions failed ${ }^{1}$. The same method was attempted with smaller pipette tips that acquire smaller tissue, occasionally using a syringe needle to push the tissue out of the pipette tip improving the PCR sensitivity ${ }^{2}$. Another study showed good sensitivity using wooden toothpicks to directly transfer DNA from the plant to the PCR reagents ${ }^{4}$.

Although some studies on Direct PCR reported sensitivity, the true positive rate, we are unaware of any reporting specificity, the true negative rate. It is essential to report both sensitivity and specificity especially when cross-contamination is a possibility. Specificity can drop all the way to zero if care is not taken to avoid cross-contamination. This is not unique to Direct PCR. Most DNA purification methods are at risk of False Positive PCR reactions due to cross-contamination. We tested 
methods analyzing their sensitivity, specificity and accuracy using Arabidopsis and rice. To address shortcomings, we developed a Direct PCR method that we call "CutTip" in which the tip of the pipette tip is cut off and dropped into the PCR reagents where it stays during the entire PCR. Our findings provide improvements that should benefit many studies.
A
Scale: $\quad 1-50$ plants
50-250 plants
250-1000 plants

Example: Routine genotyping

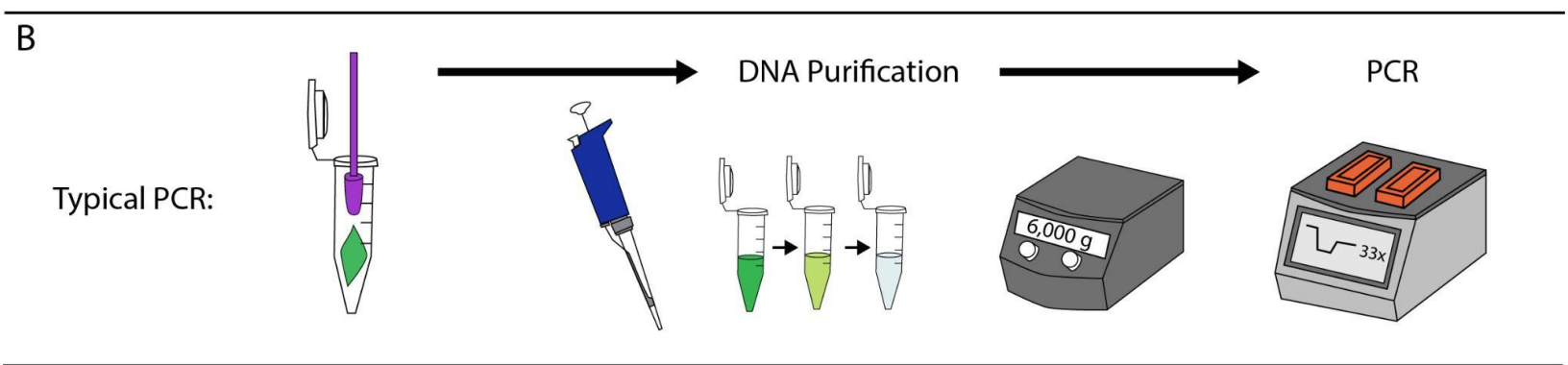

C

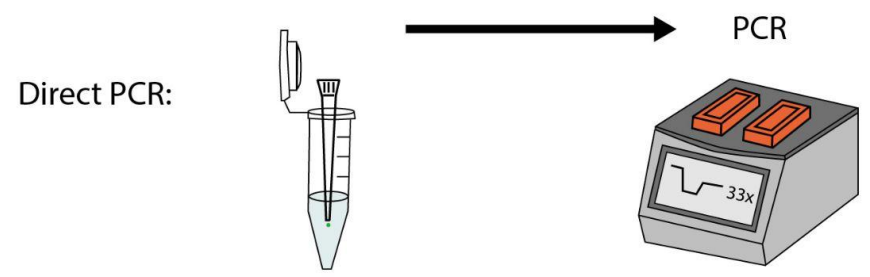

Fig. 1. Plant Direct PCR helps overcome genotyping bottlenecks. A. Plant genotyping is common at different scales. B. Typical PCR uses a DNA purification step. C. Direct PCR skips DNA purification.

\section{Results}

To get a working baseline, we attempted Direct PCR by picking tissue with tweezers and putting the tissue directly into the PCR reagents (Fig. 2A-2D). While this has been done before, we replicated it because it is simple and the most intuitive Direct PCR method. However, as reported previously, this method sometimes fails (Fig. 2C). Even adding CTAB-purified template DNA to the tubes with tissue did not increase the sensitivity (Fig. 2D). This fits with the previous findings that Arabidopsis PCR reactions containing tissue fail due to PCR inhibition caused by the tissue. In addition to the low sensitivity, it took effort to repeatedly pick only small tissues $\left(\sim 1 \mathrm{~mm}^{2}\right)$, transfer it into the solution and clean the tweezers. Therefore, we deemed this approach unpractical. 
A

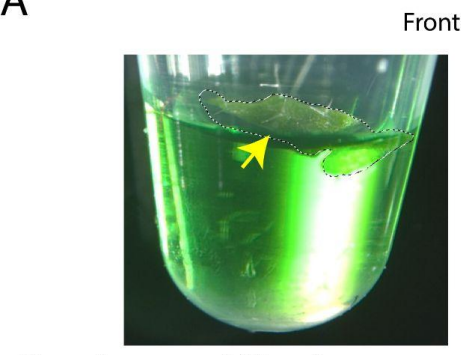

Tissue Area

$1.12 \mathrm{~mm}^{2}$
Front View

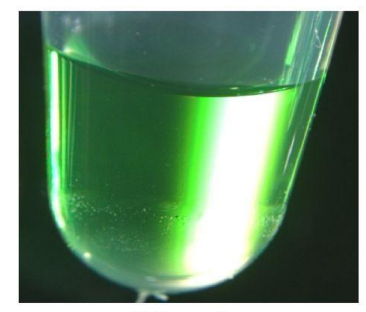

$0.0 \mathrm{~mm}^{2}$
B

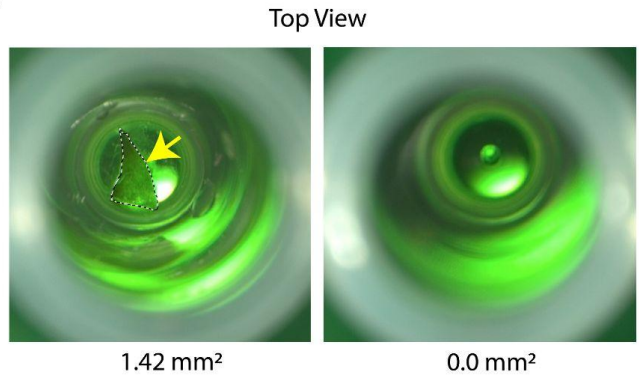

C

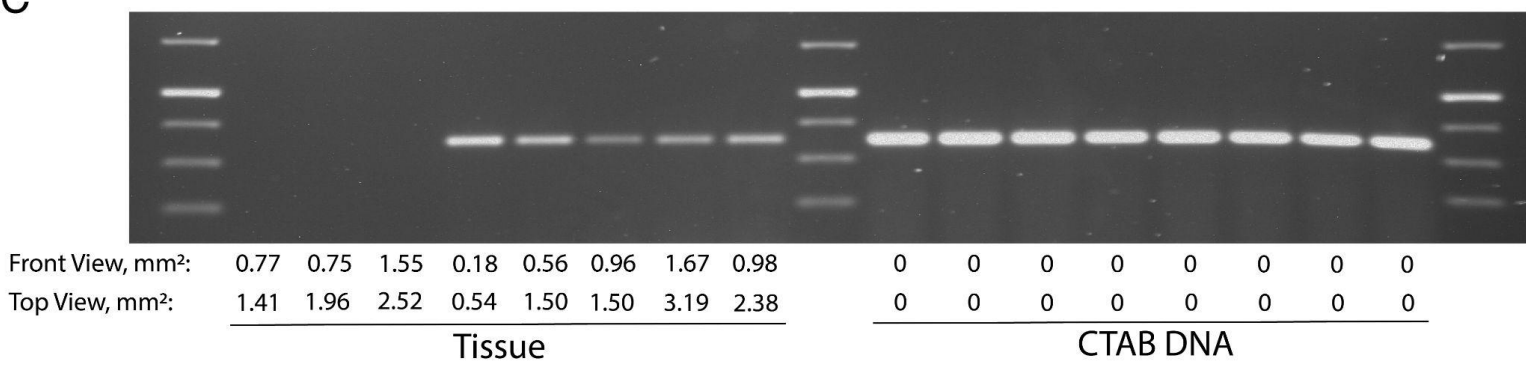

D

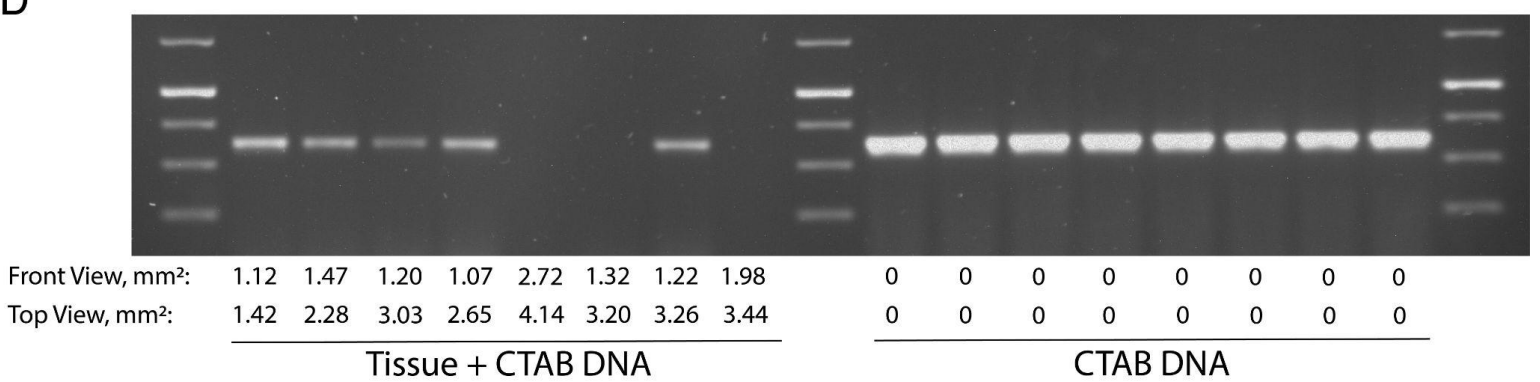

Fig. 2: Arabidopsis tissue inhibits PCR. A. Example Front View of reactions just before PCR. Area within the tissue border is measured. Yellow arrow points to tissue. B. Example Top View of reactions just before PCR. Area within the tissue border is measured. C. Result of 16 PCR reactions. The left 8 reactions contained Col-0 tissue but not CTAB DNA. The right 8 reactions contained CTAB DNA but no tissue. The numbers are estimates of the tissue size. D. All 16 PCR reactions contained the exact same reagents including a Col-0 primer pair and CTAB-purified Col-0 genomic DNA. The only difference is the left 8 reactions also received a piece of Col-0 tissue.

In preliminary work examining leaf poking methods for Direct PCR, we found that while wooden toothpicks often worked, the wood too quickly absorbed the PCR liquid (Supp. Fig. 1A, 1B). We therefore rejected the use of wooden toothpicks for poking leaves. We found that plastic toothpicks often worked. We would poke a leaf with a plastic toothpick, tap or vortex the plate with the plastic toothpicks and finally remove the plastic toothpicks before starting the PCR (Supp. Fig. 1C). When using plastic toothpicks like this, PCR sensitivities were $87.5 \%$ and $56.3 \%$ for 2 control primer pairs. We noticed that cutting the tip of the plastic toothpick and leaving it in the PCR reaction 
during the PCR potentially increased the sensitivity. The one drawback was that cutting plastic toothpicks took much physical effort due to the hardness of each toothpick (Supp. Fig. 1D). Thus, cutting toothpicks was rejected as a method. A softer material was needed. Due to the relative softness of pipette tips, we found it much easier to cut pipette tips. Overall our preliminary data suggested that Direct PCR could immediately improve our screens for mutations in plants, but the PCR accuracy of the most promising methods had to be measured.

We compared four Direct PCR methods that involved poking an Arabidopsis leaf with a pipette tip (Table 1; Fig. 3A; Supp. Table 1). We reasoned that some False Negatives could result from insufficient release of plant material into the reaction. One solution is transfer of a visible piece of tissue from the pipette tip to the reaction mix, such as the B.M. method ${ }^{1}$. Another was inspired by our preliminary experience with plastic toothpicks (Supp. Fig. 1C-1D; Fig. 3B-3I). We noted that after a poke in which visible tissue is not harvested, cell material is still present as a microscopic smear adhering on the pipette tip walls (Fig. 3G, 3I). This material might not be released by simple dipping and pipetting. We therefore cut and released into the reaction mix a 1-3 $\mathrm{mm}$ section of the pipette tip, which is the defining step of CutTip.

\begin{tabular}{|c|c|c|c|c|c|}
\hline Method & $\begin{array}{c}\text { Pipetting } \\
\text { or } \\
\text { CutTip }\end{array}$ & $\begin{array}{c}\text { Tissue } \\
\text { visible } \\
\text { by eye? }\end{array}$ & $\begin{array}{c}\text { Tissue } \\
\text { size }\end{array}$ & $\begin{array}{c}\text { Iterative } \\
\text { Cutting? }\end{array}$ & $\begin{array}{c}\text { Samples } \\
\text { per } \\
\text { pipette } \\
\text { tip }\end{array}$ \\
\hline $\begin{array}{c}\text { Berthomieu-Meyer } \\
\text { (B.M.) })^{1,2}\end{array}$ & Pipetting & $\mathrm{Y}$ & Small & N/A & 1 \\
\hline NT-Pip & Pipetting & $\mathrm{N}$ & $\begin{array}{c}\text { Absent or } \\
\text { microscopic }\end{array}$ & $\mathrm{N} / \mathrm{A}$ & 1 \\
\hline T-CutTip & CutTip & $\mathrm{Y}$ & $\begin{array}{c}\text { Small to } \\
\text { large }\end{array}$ & $\mathrm{Y}$ & $2-12$ \\
\hline NT-CutTip & CutTip & $\mathrm{N}$ & $\begin{array}{c}\text { Absent or } \\
\text { microscopic }\end{array}$ & $\mathrm{Y}$ & $2-12$ \\
\hline T-First-CutTip & CutTip & $\mathrm{Y}$ & Small & $\mathrm{N}$ & 1 \\
\hline
\end{tabular}

Table 1: The five Direct PCR methods that are compared in this analysis. Method prefix "T" means tissue on tip is visible by eye. Method prefix "NT" means no tissue on tip is visible by eye. $\mathrm{Y}=$ yes. $\mathrm{N}=$ no. $\mathrm{N} / \mathrm{A}=$ not applicable. 
A

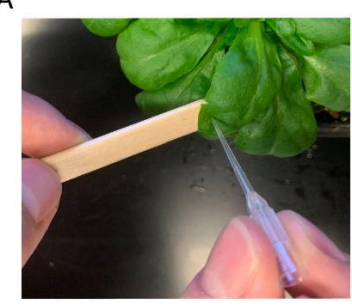

D

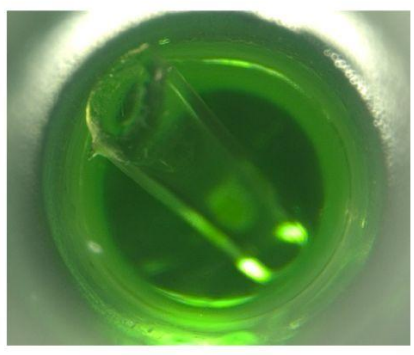

$\mathrm{F}$

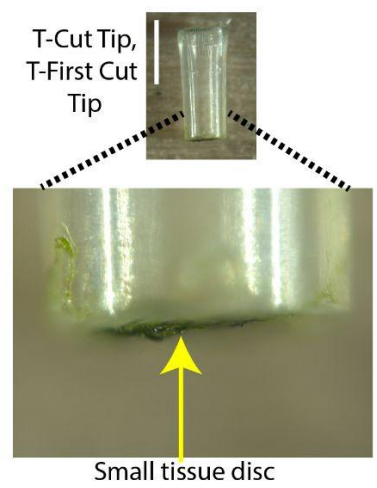

$\mathrm{H}$

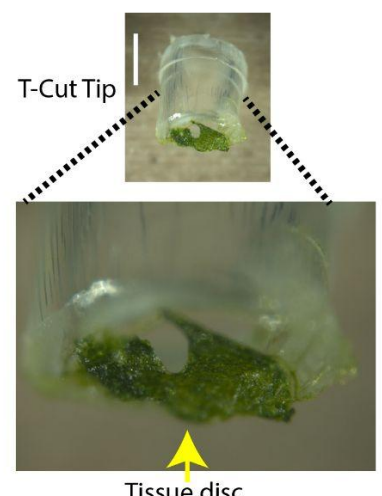

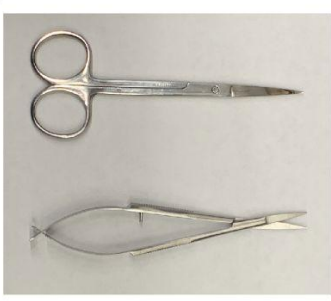

$\mathrm{E}$

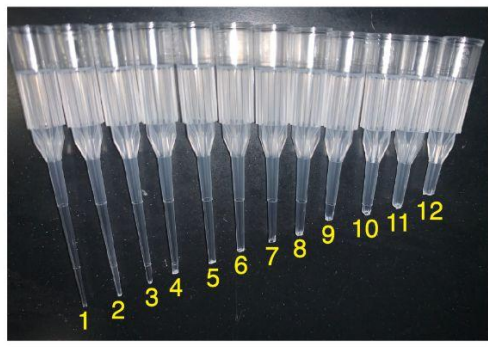

G

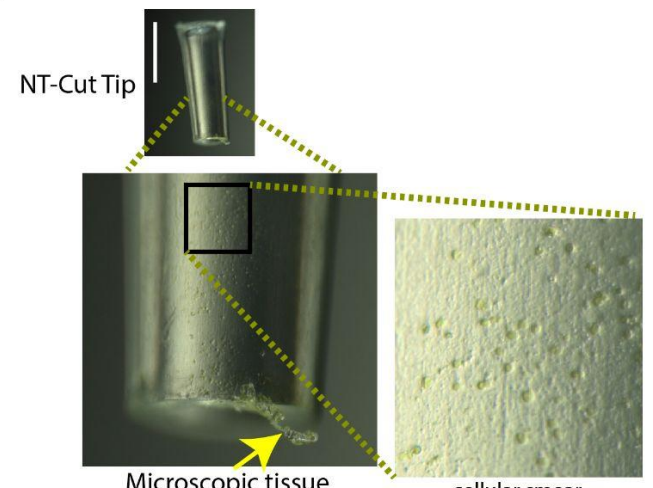

Microscopic tissue

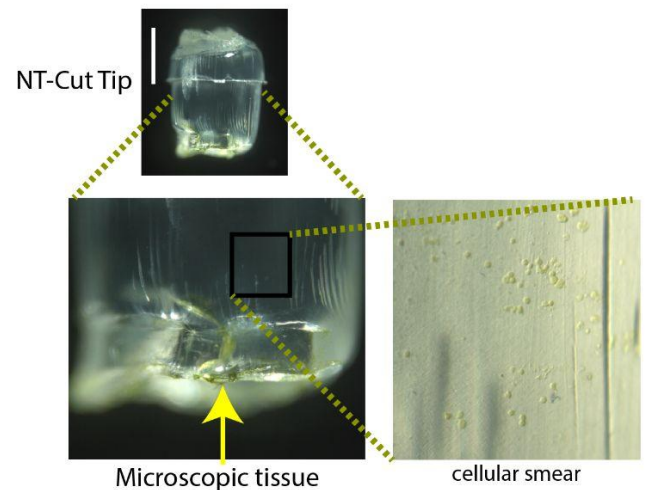

Fig. 3: CutTip PCR. A. Poking an Arabidopsis plant with a pipette tip. B. Scissors that work for CutTips. The top scissors are easy to find. The bottom scissors work faster. C. Cutting the tip into the reaction reagents. D. Cut $20 \mu \mathrm{L}$ tip in a $10 \mu \mathrm{L}$ reaction. E. A single pipette tip can be iteratively cut with different samples taken with each cut. $F$. Typical T-CutTip or T-First-CutTip. G. Typical NT-CutTip. H. Typical T-CutTip. I. Typical NT-CutTip. Panels F-G correspond to location of cut \#1 in Panel E. Panels H-I correspond to location of cut \#10 in Panel E. F-I White Bar Scale $=1 \mathrm{~mm}$. 
As a result, two of the four Direct PCR methods involved cutting the tip of the pipette tip and leaving it in the reaction (Fig. 3B, 3C and 3D; Supp. Movie 1). We created this CutTip method in an effort to ensure sufficient DNA template is in the reaction and to increase sensitivity. The basic CutTip method involves iteratively cutting up the tip, with each cut releasing a different sample into a different well. If one is careful to avoid cross-contamination, it is possible to get 12 samples from 12 cuts of a single pipette tip (Fig. 3E). The other factor used to differentiate the methods was either rejecting or selecting the presence of visible pieces of tissue on the tip after poking (Fig. $3 \mathrm{~F}, 3 \mathrm{G}, 3 \mathrm{H}$ and $3 \mathrm{I}$ ). We prefix names of methods that have no visible tissue "NT" (Table 1). If an operator aims to obtain visible tissue (methods prefixed "T" as in T-CutTip), the tissue size increases as cuts are made further up the pipette tip (Fig. 3E, 3F and 3H) eventually inhibiting the reactions and thus lowering sensitivity.

To measure sensitivity we tested for the presence of the PCR product in 20 technical replicates for each of 16 primer pairs resulting in 320 total reactions for each method at each specified number of cycles. At 24 PCR cycles, NT-Pip (meaning pipetting, no visible tissue) had the lowest sensitivity, likely due to lack of enough template DNA (Table 1; Fig. 4A). T-CutTip had the highest sensitivity. Then, we repeated the experiment using 33 cycles. At 33 cycles, all four methods reached a fairly high sensitivity, though NT-CutTip and B.M. performed best with sensitivities of $97.9 \%$ and $97.3 \%$ respectively. We attributed the slightly imperfect sensitivity to the tip not sinking in the reaction liquid when using NT-CutTip. When using the B.M. method, imperfect sensitivity was attributed to failure of tissue transfer to the solution. We hypothesized that using only the first cut of a pipette tip with visible tissue (and discarding the rest of the pipette tip), called T-First-CutTip, would address both above problems and the tissue inhibition problem. T-First-CutTip includes only the very first cut of a tip, whereby the visible but small tissue can contact the solution. Thus, T-First-CutTip has two chances for template DNA to come into contact with the solution: 1) the cellular smear and 2) the visible small tissue. Using 8 different primer pairs, T-First-CutTip had a slightly higher average sensitivity than NT-CutTip, with $100 \%$ and 99.0\% sensitivity respectively (Fig. 4B). Either method has sufficient sensitivity for most experiments.

In conclusion, B.M., T-First-CutTip and NT-CutTip provide high sensitivity. We next addressed specificity. To see how well Direct PCR can avoid amplifying incorrect sequences and cross-contamination, for each method we tested PCR amplification in 12 technical replicates for each of 8 primer pairs that are not expected to produce a product. We alternated pokes of real positives (Ler) and real negatives (Col-0). Overall 
A

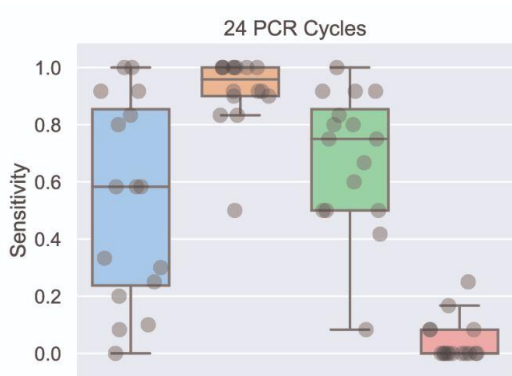

C

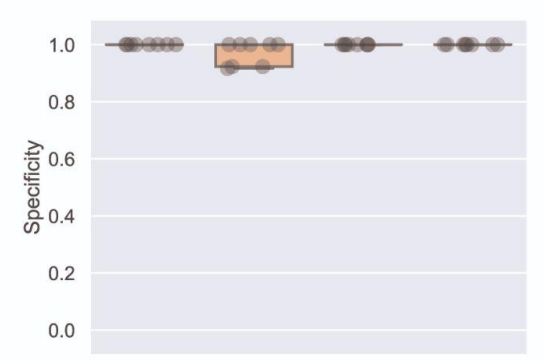

$\mathrm{E}$

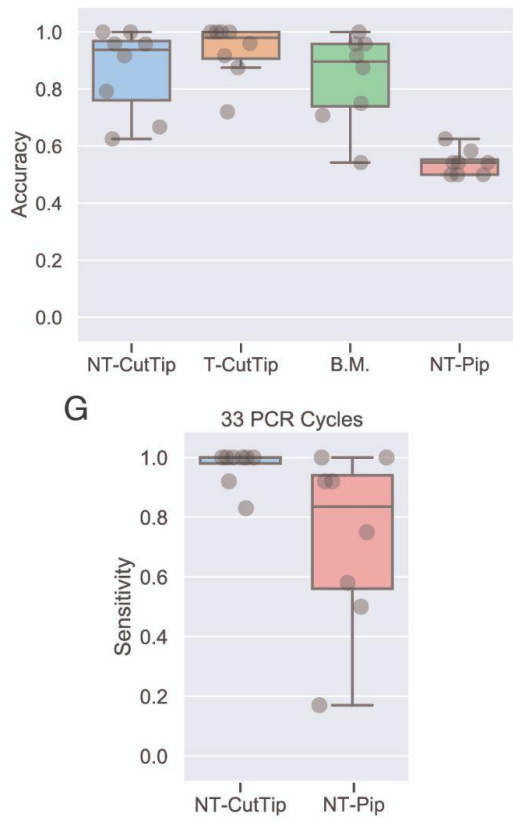

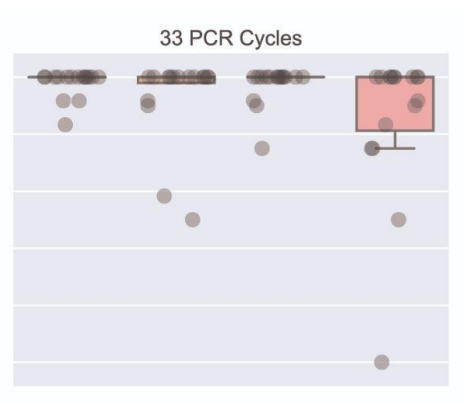
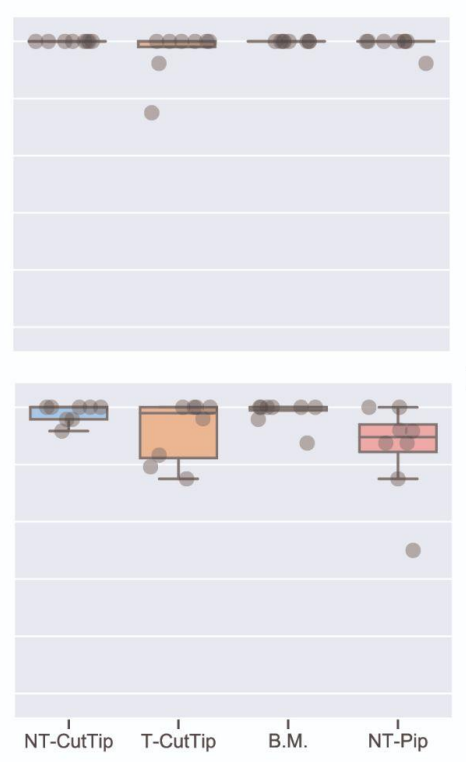

$\mathrm{H}$

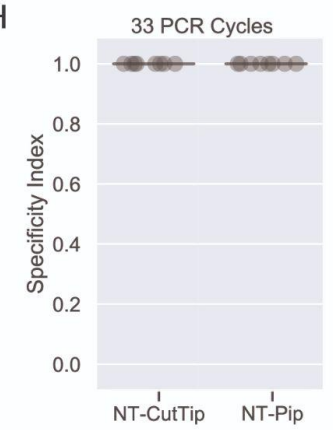

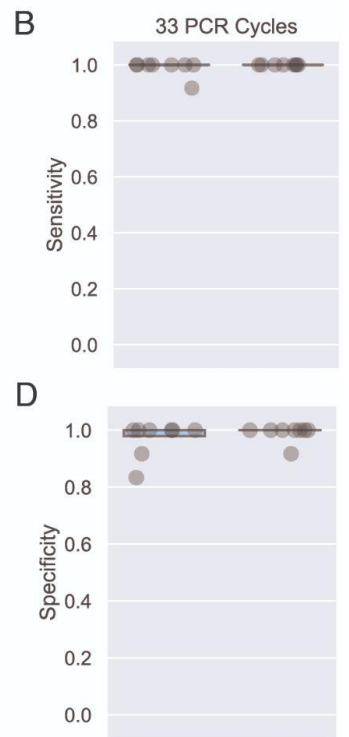

$\mathrm{F}$
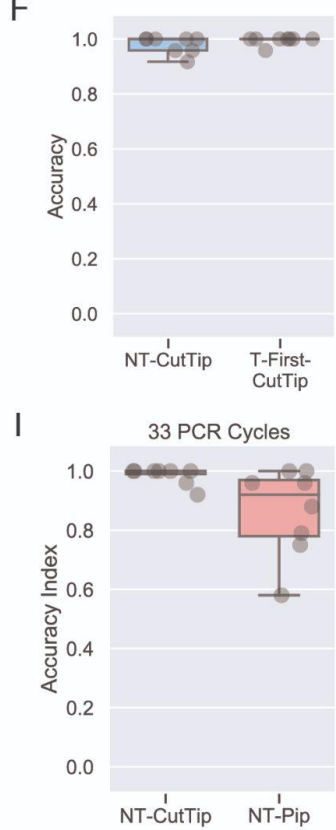

Fig. 4. Accuracy of Direct PCR using Arabidopsis and rice. A.-F. Accuracy using Arabidopsis. A. Sensitivity using 4 Direct PCR methods. Each dot represents 1 of 16 primer pairs. B. Sensitivity after lessons from panel A. C. Specificity using 4 Direct PCR methods. Each dot represents 1 of 8 primer pairs. D. Specificity after lessons from panel C. E. Accuracy using 4 Direct PCR methods. F. Accuracy after lessons from panel E. G.-I. Accuracy using Rice. G. PCR Sensitivity Index of NT-CutTip and NT-Pip. H. PCR Specificity Index of NT-CutTip and NT-Pip. I. PCR Accuracy Index of NT-CutTip and NT-Pip. 
the specificity was high (Fig. 4C and 4D). The overall lack of bands of incorrect size in these PCRs suggest that the imperfect specificities were due mostly to template cross-contamination from the cut with a Ler poke to the cut with a Col-0 poke, i.e. by template reaching the next cut segment. We hypothesized that T-First-CutTip would solve this problem because that method has no iterative cuts, meaning that each pipette tip is used for only one poke and the rest of the pipette tip is discarded. Indeed, T-First-CutTip had higher specificity than NT-CutTip, with $99.0 \%$ and $96.9 \%$ respectively. Thus, NT-CutTip had $100 \%$ specificity in its first trial and $96.9 \%$ specificity in its second trial (Fig. 4C and 4D). We believe the lower specificity of NT-CutTip in the second trial was due to the leaves being unusually plump and curvy that week. Thus, the properties of the tissue being sampled should be evaluated with common sense when using iterative pipette tip cutting.

Accuracy, measured as $(\mathrm{TP}+\mathrm{TN}) /(\mathrm{TP}+\mathrm{TN}+\mathrm{FP}+\mathrm{FN})$, is a summary composite of both sensitivity and specificity. Based on their sensitivities and specificities, it is not surprising that NT-CutTip, B.M. and T-First-CutTip had the highest accuracies. B.M. and NT-CutTip both had $97.9 \%$ accuracy (Fig. 4E and 4F). When compared to T-First-CutTip, T-CutTip again had accuracy $97.9 \%$ while T-First-CutTip had accuracy 99.5\%. Practicality and accuracy are the critical criteria for method choice. While preparing the above 2,597 PCR reactions, we found that NT-CutTip had the fewest practical drawbacks of the five pipette tip methods (Table 2). Overall this suggests NT-CutTip and T-First-CutTip are the better methods for high-throughput genotyping, though B.M. has the same accuracy as NT-CutTip.

Next we measured Direct PCR accuracy with rice. Sensitivity of Direct PCR was measured in rice using NT-First-CutTip and p1000 tips, though p20 tips also work (Fig. $4 G)$. In an effort to ensure our results would translate to other researchers' rice genotyping, 8 random target loci were chosen in the first few megabases of chromosomes 4-7. The average sensitivity of NT-Pip in rice was $73.0 \%$ (Fig. $4 \mathrm{H})$. The average sensitivity using NT-First-CutTip was $96.9 \%$. Instead of directly measuring specificity and accuracy, we measured a Specificity Index and Accuracy Index as explained in Materials and Methods. According to our measurements, both rice techniques had an average Specificity Index of 100\%. The average Accuracy Index was 86.5\% for NT-Pip and $98.5 \%$ for NT-First-CutTip (Fig. 4I; Supp. Table 2). Thus, NT-CutTip is an accurate Direct PCR method for rice genotyping.

To demonstrate the use of Direct PCR to detect a CRISPR-induced mutation of interest in Arabidopsis, we used CutTip to look for the mutation at many different leaves in 3 primary transformants expressing Cas9. The Cas 9 forms a DNA double strand break and we looked for mutations that would be formed by Non-Homologous End Joining ${ }^{9-11}$. The expected mutation was a $2.3 \mathrm{~kb}$ deletion between protospacers that are in non-coding sequences of the gene $\mathrm{CH1}$ (At1G44446) (Fig. 5A). A homozygous deletion of the DNA segment between the 2 protospacers would result in a pale color 
phenotype. The 3 primary transformants were dark green with no pale sectors. We did an initial NT-CutTip PCR on 8-12 leaves of each primary transformant. Only one reaction resulted in an electrophoresis band, suggesting mosaic presence of the deletion in one primary transformant. Forty-six more NT-CutTip PCRs in different leaves of the same primary transformant clearly delineated a single small inflorescence that contained the deletion of interest (Fig. 5B). Progeny from a silique from the small inflorescence were planted in a single pot. The segregation of phenotype and deletion was as expected for germline transmission of the deletion (Fig. 5C).

A

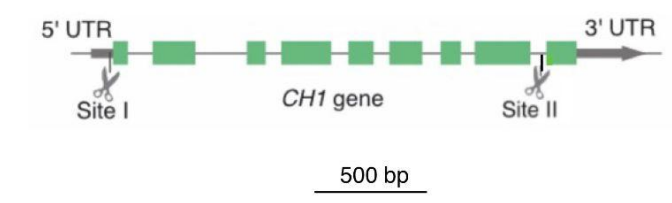

C

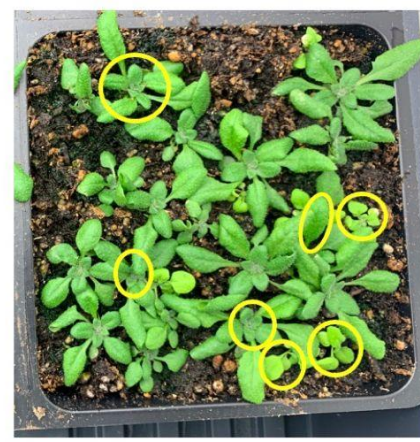

B

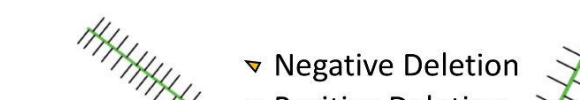

- Positive Deletion

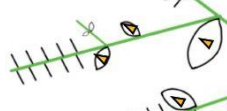

Positive Deletion

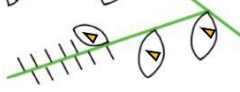

Segregation of progeny

from silique of interest
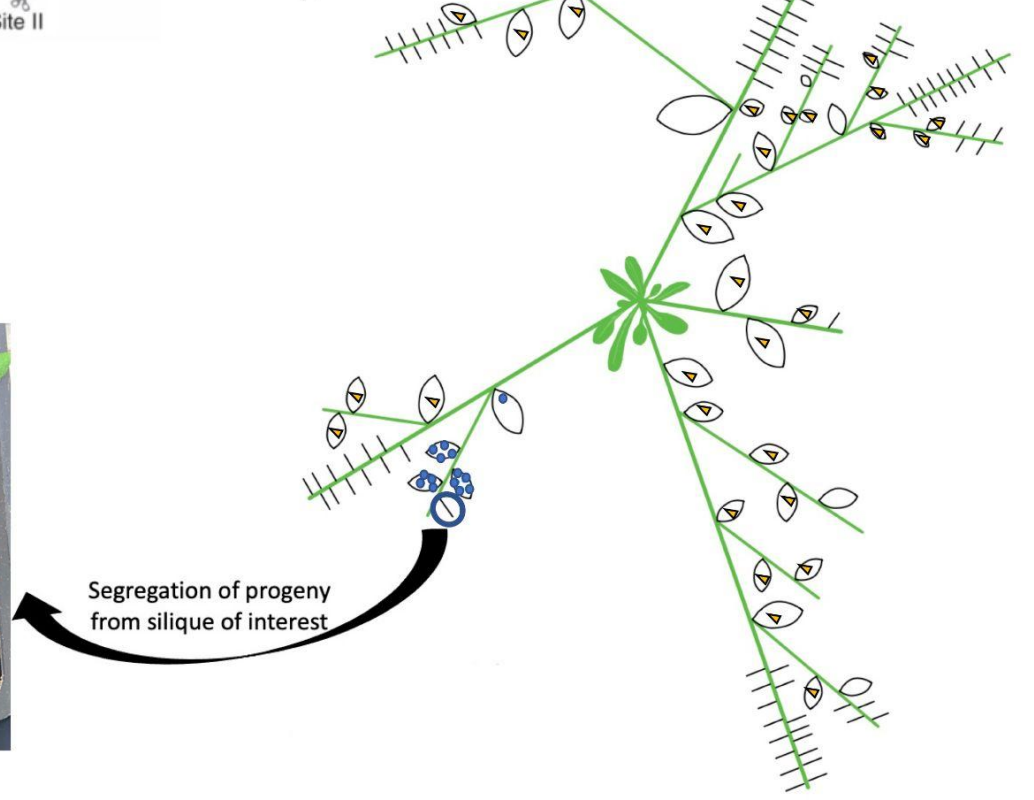

Fig. 5: CutTip PCR used to scan plants for a $2.3 \mathrm{~kb}$ CRISPR-induced deletion. A. Gene map of Arabidopsis $\mathrm{CH} 1$ and location of $2 \mathrm{CRISPR}-\mathrm{Cas} 9$ targets. B. Location of NT-CutTip sampling on a single primary transformant and PCR results. The sector that contains the desired DNA deletion has no visible phenotype on the primary transformant. C. Plants with a yellow circle are the Cas9-negative progeny that contain the $2.3 \mathrm{~kb}$ deletion.

Possibly the most common CRISPR-induced mutation is a single base insertion, in which the inserted base is the same as the 4 th base in the protospacer ${ }^{10}$. We had a population of T2 rice plants in which we were looking for a CRISPR-induced single base pair insertion. Since the target contained no restriction sites and Sanger sequencing all of the plants would be too expensive, we tried using a primer in which the 3' end would 
pair with the desired mutated base (Fig. 6A). For all of the genotyping we used NT-CutTip PCR using p20 tips, and cut iteratively as was done with Arabidopsis. We looked for the non-mutated sequence and the mutation of interest. Using the modified primer, no product was generated from the WT rice, yet the product was generated from 9/18 of the T2 plants (Fig. 6B). To find the mutation in the Cas9-free background, progeny from one of the positive T2s was grown. Three of the nine T3 siblings were Cas9-free (Fig. 6C). One of the three Cas9-free plants was shown to contain the mutation of interest (Fig. 6D and 6E). This shows the ability for NT-CutTip to efficiently find CRISPR-induced single-base mutations in rice.

A

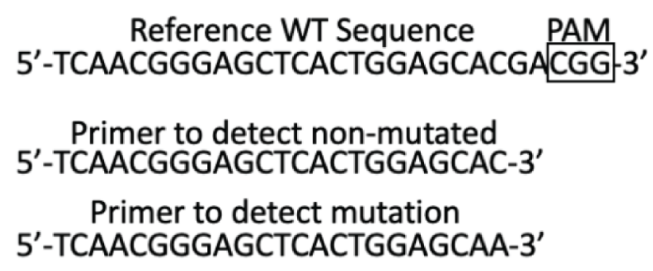

C

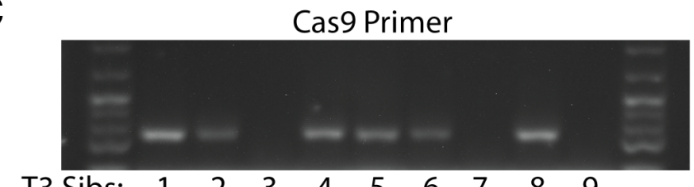

$\mathrm{D}$

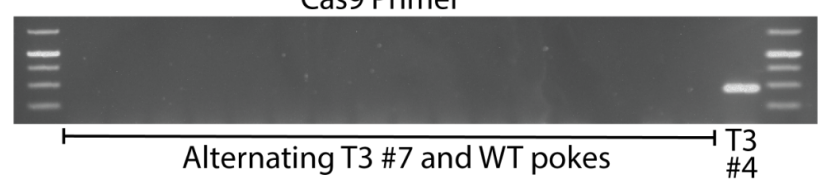

B

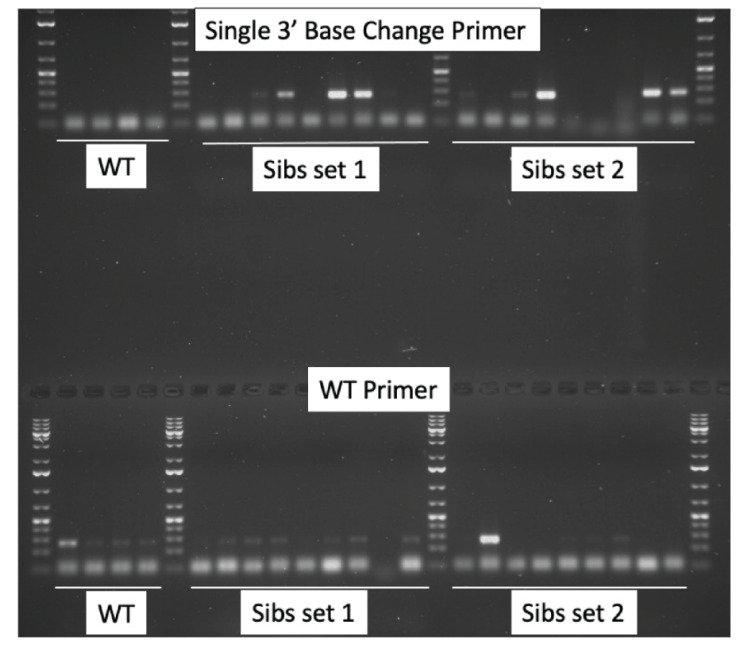

E

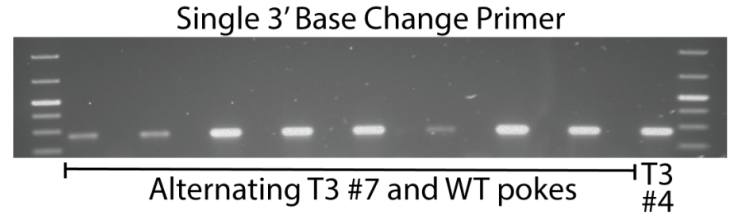

Fig. 6: CRISPR-induced mutation detected in rice. A. CRISPR Target locus and PCR primer for mutation detection. B. NT-CutTip PCR to detect non-mutated and mutated sequences in T2 siblings. C. NT-CutTip PCR to detect Cas9 presence in a set of T3 siblings. D. NT-CutTip PCR to confirm Cas9 absence in T3 sibling \#7. E. NT-CutTip PCR to confirm presence of desired mutation in T3 sibling \#7. Note: Panels B and C are 44 PCR cycles. Panels D and E are 40 PCR cycles.

Another concern is practicality and accessibility. We used the everyday PCR Master Mix that was already available in the lab. All PCRs were prepared at room temperature. Regarding stability at room temperature, we prepared the PCRs and walked to and from the growth chambers at room temperature for a total of about 2 hours before the PCR plates were put in the thermal cycler for all of Figs. 4, 5 and 6 . 


\begin{tabular}{|c|c|c|}
\hline Method & Pros & Cons \\
\hline B.M. & $\begin{array}{l}\text { 1) High accuracy. } \\
\text { 2) Long, thin tip. }\end{array}$ & $\begin{array}{l}\text { 1) Difficulty acquiring tissue. } \\
\text { 2) Uses many pipette tips. } \\
\text { 3) Pipetting step. } \\
\text { 4) Tissue gets stuck in tip and on tube wall. }\end{array}$ \\
\hline NT-Pip & $\begin{array}{l}\text { 1) Relatively easy. } \\
\text { 2) Fast. } \\
\text { 3) Long, thin tip. }\end{array}$ & $\begin{array}{l}\text { 1) Moderate accuracy. } \\
\text { 2) Uses many pipette tips. } \\
\text { 3) Pipetting step. }\end{array}$ \\
\hline T-CutTip & 1) Uses few pipette tips. & $\begin{array}{l}\text { 1) Difficulty acquiring tissue. } \\
\text { 2) PCR inhibition due to larger tissue when } \\
\text { cutting iteratively. } \\
\text { 3) Tissue gets stuck on tube wall. } \\
\text { 4) Cut tip is in the reaction tube. } \\
\text { 5) Relatively slow. } \\
\text { 6) Risk of cross-contamination if not careful. }\end{array}$ \\
\hline NT-CutTip & $\begin{array}{l}\text { 1) High accuracy. } \\
\text { 2) Uses few pipette tips. } \\
\text { 3) Fast. } \\
\text { 4) Relatively easy. }\end{array}$ & $\begin{array}{l}\text { 1) Cut tip is in the reaction tube. } \\
\text { 2) Risk of cross-contamination if not careful. }\end{array}$ \\
\hline $\begin{array}{l}\text { T-First- } \\
\text { CutTip }\end{array}$ & $\begin{array}{l}\text { 1) High accuracy. } \\
\text { 2) Long, thin tip. }\end{array}$ & $\begin{array}{l}\text { 1) Difficulty acquiring tissue. } \\
\text { 2) First cut doesn't easily fall. } \\
\text { 3) Uses many pipette tips. } \\
\text { 4) Cut tip is in the reaction tube. } \\
\text { 5) Tissue gets stuck on tube wall. }\end{array}$ \\
\hline
\end{tabular}

Table 2: Pros and cons of each tested Direct PCR method. 
This suggests that Direct PCR can be prepared in the greenhouse or in the field, though we suggest chilling the plate if it is expected to take more than 2 hours to prepare the PCR. Most of the Direct PCR materials can be kept in a kit that can be taken to or stored with the plants, enabling PCR preparation and possibly PCR completion in the field (Supp. Fig. 2).

\section{Discussion}

When choosing a PCR method, a researcher's foremost concern might be accuracy. This would be the case, for example, in CRISPR screens in plants where false positives for the desired change and false negatives for the presence of the CAS gene can compromise a project. Another concern is cost and practicality of high throughput screens. To help address these concerns through Direct PCR, we explored published and new variations of this method. We report practices that are compatible with high throughput studies and that at the same time maximize accuracy. We demonstrate their use in facilitating CRISPR editing of Arabidopsis and rice.

We had generated populations of Arabidopsis and rice plants in order to find specific genome edits, but we had noticed mosaicism that complicated the search for edits transmitted through the germline. When CRISPR causes rare edits or mosaicism, one approach to finding the mutation of interest is to pool tissues from many plants or many locations on a single plant followed by CTAB-purification. Pooling tissues typically works fine but we have lacked an efficient method to locate the mutated sector in a follow up. Our preferred method for searching for mutated sectors has become NT-CutTip due to its high accuracy and practicality. Poking the plant tissue coats the pipette plastic surface with a monolayer of cells (Fig $3 G, I)$, from which we assume that DNA is released upon heating during the PCR. NT-CutTip enables the researcher to genotype many samples with very little effort. That is why we used NT-CutTip to search for a CRISPR-induced $2.3 \mathrm{~kb}$ deletion, and we found the deletion in a small inflorescence (Fig 5B). Without that broad scan of many locations in each primary transformant, we could have completely missed the deletion in that batch of primary transformants.

Researchers desire to find a CRISPR-induced mutation in progeny that lack a CRISPR transgene. This means hundreds or thousands of progeny are screened for a Cas9-free plant that contains the mutation of interest. While fluorescent markers are great for transgene detection, NT-CutTip is also suitable for the task. We used NT-CutTip in both Arabidopsis and rice to find mutations in Cas9-free progeny. Clearly NT-CutTip can be used to detect other prized DNA edits including homologous recombination, base edits and CRISPR Prime edits ${ }^{12}$.

Given CTAB, Direct PCR and intermediate methods, there are many valid methods to prepare a PCR template. We demonstrate high accuracy of some of the simplest plant Direct PCR methods to date, specifically the B.M. and CutTip methods. 
Manufacturing specialized tools might further improve the accuracy, speed and practicality of the method (Supp. Fig. 4). The accuracy and speed of CutTip and B.M. enable genotyping more plants and more locations on a plant, which is often important for plants undergoing fresh genome-editing. The ease also enables PCR preparation in the field. Overall, quickly and confidently genotyping more plants in more locations on the plants should improve experiment results and completion.

\section{Materials and Methods}

\section{Choosing loci and designing primers}

The end goal is to measure the sensitivity and specificity of attaining bands that we assume contain a predetermined base of interest. Some loci did not amplify including when using CTAB-purified genomic DNA and were excluded. Eight Col-0 and 8 Ler loci were amplifiable using CTAB-purified DNA and used to measure Direct PCR with Arabidopsis. For Arabidopsis Col-0, loci were chosen based on materials that we had available from other experiments. Arabidopsis Ler-specific primers were chosen based on having smaller expected band sizes as compared to Col-0 ${ }^{13}$. We had never attempted amplification of 6/8 of the Col-0 loci and 7/8 of the Ler loci, and therefore we believe the selected loci were minimally biased. For rice, bases of interest were randomly selected from within segments of 1-5 megabases of Chromosomes 4-7. No base of interest was changed or removed during this study. Overall we believe the loci we chose to genotype are representative of what researchers typically encounter in Arabidopsis and rice.

Candidate primer sequences were chosen by manually looking upstream and downstream of the base. Desired characteristics included mixing of all 4 nucleotides especially on the 3' side, avoidance of repeats, a G or C at the 3' end, 26-31 nucleotide length and 150-500 bp between primers of each pair. The "PCR Primer Stats" tool on www.bioinformatics.org was used to find and avoid primer self-annealing. All chosen rice primers worked well. All except three Arabidopsis primers worked, mostly due to Ler sequence not matching the reference. The 3 non-performing Arabidopsis primer pairs were replaced with alternative primers that amplify the same locus, which was allowed because it is a common optimization step regardless of the method of PCR and DNA purification. Primers are listed in Supp. Tables 1 and 2.

\section{Direct Tissue vs. CTAB}

What we call "CTAB DNA" is Col-0 DNA that was purified using a CTAB protocol ${ }^{14}$. Fresh tissue was frozen with liquid nitrogen and ground with a pestle. Five-hundred $\mu \mathrm{L}$ CTAB extraction buffer was added, then shaken. One-hundred fifty $\mu \mathrm{L}$ 50:1 Chloroform:Isoamyl Alcohol was added and shaken. After centrifuging 4,000 g for 
5 minutes, the CTAB layer was transferred to a tube containing $200 \mu \mathrm{L}$ isopropanol and shaken. After centrifuging $8,000 \mathrm{~g}$ for 5 minutes, the isopropanol was poured out and $400 \mu \mathrm{L} 70 \%$ ethanol was added. The $70 \%$ ethanol was immediately poured out. The purified DNA was air dried at $37^{\circ} \mathrm{C}$ for about 1 hour. The DNA was dissolved in nuclease-free water.

For the Direct Tissue PCR, tissue was simply picked with tweezers and then tapped into the tube. For estimated the size of the tissue, front and side images of each tube were taken using a dissecting microscope. Adobe Photoshop 2021 was used to roughly estimate the tissue Area using the Lasso tool and Image -> Analysis.

\section{Pipetting Direct PCR}

Pipetting tissue Direct PCR was done as originally described ${ }^{1,2}$. For Arabidopsis, a $20 \mu \mathrm{L}$ pipette tip was poked through a leaf, using a flat wooden toothpick or popsicle stick as a surface to press against (Fig. 3A). The pipette tip was then placed onto the pipette and pipetted up and down 10 times in the PCR solution. For rice, a $1000 \mu \mathrm{L}$ pipette tip was poked through a leaf, using a popsicle stick as a surface. After removing the pipette tips, the reaction plate was sealed, briefly vortexed, briefly centrifuged and then the PCR reaction was started.

\section{CutTip Direct PCR}

Materials are shown in Supp. Fig. 2. A visual protocol can be viewed in Supp. Movie 1. The CutTip method starts with the same steps as the Pipetting Direct PCR methods (Fig. 3A). The only difference is that, in CutTip, the tip of the pipette tip is cut off and dropped into the reaction well that already contains all of the PCR reagents (Fig. 3B, 3C). Common cosmetic scissors work satisfactorily, though we prefer push spring scissors due to ease of use (Fig. 3B). We use model HTS 144S7 4.5" Straight Stainless Steel Squeeze Scissors purchased from www.amazon.com. The CutTip stays in the reaction during the PCR and we never remove the CutTip. For Arabidopsis we use 20 $\mu \mathrm{L}$ pipette tips, and either a flat wooden toothpick or popsicle stick as a surface to press on. For accuracy measurement with rice we use T-First-CutTip with $1000 \mu \mathrm{L}$ pipette tips and only popsicle sticks as a surface, though a $20 \mu \mathrm{L}$ tip works. For rice in Fig. 6 we used NT-CutTip with iteratively cut p20 pipette tips exactly like we did NT-CutTip with Arabidopsis. We alternated many real positive samples with negative controls that did not involve poking tissue but did receive a CutTip. For measuring specificity and accuracy, we alternated every positive plant with a negative plant so that we could get a minimally biased measure of cross-contamination. When measuring sensitivity but not accuracy nor specificity, we interspersed each set of 10 positive samples with 4 negative controls that received a CutTip but presumably no template DNA.

What we call CutTip involves iteratively cutting up the pipette tip so that 1-12 samples can be taken using a single pipette tip. What we call First CutTip involves using 
only the very first cut of a pipette tip, then discarding the pipette tip, meaning only 1 sample for each pipette tip.

Errors occur when learning how to do this technique. One error is not getting the CutTip into the liquid, which occurs more with the lightweight $20 \mu \mathrm{L}$ tips than the heavier $1000 \mu \mathrm{L}$ tips. The scissors and tips can be angled and placed next to the liquid to get all CutTips into their liquid (Fig. 3B). Another source of error is the scissors causing cross-contamination between wells. To minimize cross-contamination, we use a double dip system to clean the scissors between each sample. The scissors are first dipped into a tube of water, then wiped with a wet paper towel. The scissors are then dipped into a second tube of water, then wiped with a dry paper towel. Typically the next sample can use the same tube of water and paper towel. See Supp. Table 3 for more troubleshooting guidance.

\section{PCR}

All PCRs were performed in $10 \mu \mathrm{L}$ reactions on Bio-Rad 96-well thermocyclers. Each reaction contained $5 \mu \mathrm{L}$ water (Hyclone), $4 \mu \mathrm{L}$ 2X GoTaq Green Master Mix and 1 $\mu \mathrm{L} 5 \mathrm{uM}$ primer pair. The poked leaf DNA was added by either Pipetting or a CutTip as described above. The only PCR parameters that varied were annealing temperature, elongation time and number of cycles (Supp. Table 1). Annealing temperatures were chosen by NEB Tm Calculator and ranged $50-61{ }^{\circ} \mathrm{C}$ (version 1.13.0). Elongation time was 33-55 seconds, depending on amplicon length and preliminary PCRs using CTAB-purified DNA. Every PCR reaction was within these thermal cycler parameters:

$$
\begin{aligned}
& \text { Step 1: } 120 \text { seconds, } 95^{\circ} \mathrm{C} \\
& \text { Step 2: } 15 \text { seconds, } 95{ }^{\circ} \mathrm{C} \\
& \text { Step 3: } 30 \text { seconds, } \mathrm{X}^{\circ} \mathrm{C} \\
& \text { Step 4: } \mathrm{Y} \text { seconds, } 72{ }^{\circ} \mathrm{C} \\
& \text { 24-40 cycles of steps } 2-4 \\
& \text { Step 5: } 2: 00,72{ }^{\circ} \mathrm{C} \\
& \text { Step 6: } 14{ }^{\circ} \mathrm{C} \text { until removed }
\end{aligned}
$$

\section{Sensitivity, Specificity and Accuracy}

For Arabidopsis, the unit of measurement was the presence or absence of a band at an expected band size. Depending on whether the band was expected in a reaction, the result of each reaction could be classified as a True Positive (TP), True Negative (TN), False Positive (FP) or False Negative (FN). The following formulas were used for sensitivity, specificity and accuracy :

$$
\text { Sensitivity }=\text { TP / (TP + FN) }
$$




$$
\begin{gathered}
\text { Specificity }=\mathrm{TN} /(\mathrm{TN}+\mathrm{FP}) \\
\text { Accuracy }=(\mathrm{TP}+\mathrm{TN}) /(\mathrm{TP}+\mathrm{TN}+\mathrm{FP}+\mathrm{FN}) ; \text { with } \mathrm{TP}+\mathrm{FN}=\mathrm{FP}+\mathrm{TN}
\end{gathered}
$$

Directly measuring specificity requires having a clear and relevant definition of TN. We believe this was achieved for Arabidopsis by defining TN as a PCR band that is expected from Ler but not expected from the closely related ecotype Col-0. Alternating each real Negative poke (Col-0) with a real Positive poke (Ler) was essential for correct measurements of specificity.

For our rice population, there are technical and feasibility hurdles regarding the measurement of specificity. Due to the invariable presence of the TP band, we lack the ability to do a simple specificity test. The rice loci were random and not designed to have great restriction sites. Even if we successfully digested or sequenced every band, the samples still would not fit the strict definition that TN does not produce the band to begin with. Due to such problems, we decided to define and use a Specificity Index for rice rather than directly measuring specificity. We define the Specificity Index as the presence vs. absence of PCR bands of sizes different from the TP band. Thus, the Specificity Index is a measure of noise bands. Vague electrophoretic DNA smears and primer dimer products were not counted in the Specificity Index.

$$
\begin{gathered}
\text { Specificity Index }=(\text { Noiseless }) /(\text { Noiseless }+ \text { Noisy }) \\
\text { Accuracy Index }=(\text { TP }+ \text { Noiseless }) /(T P+\text { Noiseless }+ \text { Noisy }+ \text { FN }) \\
\text { with TP }+ \text { FN }=\text { Noisy }+ \text { Noiseless }
\end{gathered}
$$

\section{Plant growth}

Arabidopsis was grown on Sunshine Mix \#1 soil fertilized by UC Davis Controlled Environment Facility (CEF) nutrient water. The light cycle was 14 hours light and 10 hours dark. The temperature was $17-24{ }^{\circ} \mathrm{C}$. For measurement of sensitivity, specificity and accuracy, genotyping was performed using the healthiest leaves at the 6 leaf to first bolt stage. Rice was grown on a 16 hour light cycle with Sunshine Mix \#1 soil fertilized by UC Davis CEF nutrient water. The temperature was a constant $24{ }^{\circ} \mathrm{C}$. Rice genotyping was performed using the healthiest leaves on 1-2 month old plants. Any visible green Arabidopsis and rice tissue that we have tested have successfully yielded Direct PCR bands, but we only measured sensitivity, specificity and accuracy using the tissues stated above. 


\section{CRISPR cloning}

The CRISPR construct for Arabidopsis was derived from pEn-Chimera for proAtU6-26 guide RNAs, pPLV02-RC9 for proRPS5a-Cas9 and pEARLEYGATE302-v2 for Gateway construction ${ }^{15-17}$. The final plasmid was electroporated into Agrobacterium tumefaciens strain GV3101. Floral Dip was used to transform the Arabidopsis. Primary transformants were selected on $1 / 2$ strength Murashige Skoog agar containing $15 \mathrm{ug} / \mathrm{mL}$ glufosinate-ammonium, then transplanted to Sunshine Mix \#1 soil. For rice, guide RNA sequences corresponding to 2 CRISPR-Cas9 targets were inserted into the plasmid pRGEB32 (Addgene plasmid \# 63142 ; http://n2t.net/addgene:63142 ; RRID:Addgene_63142). The plasmid, called pRGEB32-NP03, was electroporated into A. tumefaciens EHA105. At the UC Davis Plant Transformation Facility, Oryza sativa L. ssp. Japonica cv. 'Kitaake' callus was transformed with the pRGEB32-NP03, selected on hygromycin, and plants were regenerated.

\section{Acknowledgements}

This work was funded by an Innovative Genomics Institute grant and an NSF-Plant Genome IOS Grant 144612: Rapid and Targeted Introgression of Traits via Genome Elimination. P.G.L. was supported by an NSF Graduate Research Fellowship, Elsie Taylor Stocking Fellowship and Eric and Louise Conn Graduate Student Award in Plant Biochemistry. We thank Nimrat Kaur for video editing. We thank Brett Pike for help with plasmid construction, Maria Ximena Anleu Gil for contributing figure art, Thu Nguyen, Yinuo Zhang, and Varun Viswanath for technical support and Isabelle Henry for discussion.

\section{Author contributions}

P.L. and L.C. wrote the manuscript, made figures, acquired funding and supervised the research. P.L. conceptualized and managed the project. P.L. and P.O.K. developed methodology and curated data. P.L., L.C. and P.O.K. analyzed the data. P.L., P.O.K. and E.M. performed the experiments. E.H.T. and K.H. provided plasmids and plants. 


\section{References}

1. Berthomieu, P. \& Meyer, C. Direct amplification of plant genomic DNA from leaf and root pieces using PCR. Plant Mol. Biol. 17, 555-557 (1991).

2. Rogers, H. J. \& Parkes, H. C. Direct PCR amplification from leaf discs. Plant Sci. 143, 183-186 (1999).

3. Berendzen, K. et al. A rapid and versatile combined DNA/RNA extraction protocol and its application to the analysis of a novel DNA marker set polymorphic between Arabidopsis thaliana ecotypes Col-0 and Landsberg erecta. Plant Methods 1, 4 (2005).

4. Ohta, S. et al. A sample preparation method for direct and non-direct PCR in woody plants. J. Japan. Soc. Hotic. Sci. 82, 14-21 (2013).

5. Shiokai, S., Kitashiba, H., Shirasawa, K., Nagano, K. \& Nishio, T. Leaf-punch method to prepare a large number of PCR templates from plants for SNP analysis. Mol. Breed. 23, 329-336 (2009).

6. Werner, O., Ros, R. M. \& Guerra, J. Direct amplification and NaOH extraction: two rapid and simple methods for preparing bryophyte DNA for polymerase chain reaction (PCR). Journal of Bryology vol. 24 127-131 (2002).

7. Li, F.-W., Kuo, L.-Y., Huang, Y.-M., Chiou, W.-L. \& Wang, C.-N. Tissue-direct PCR, a rapid and extraction-free method for barcoding of ferns. Mol. Ecol. Resour. 10, 92-95 (2010).

8. Ben-Amar, A. \& Mliki, A. Timely gene detection assay and reliable screening of genetically engineered plants using an improved direct PCR-based technology. 
Transgenic Res. 30, 263-274 (2021).

9. Jinek, M. et al. A programmable dual-RNA--guided DNA endonuclease in adaptive bacterial immunity. Science 337, 816-821 (2012).

10. Lemos, B. R. et al. CRISPR/Cas9 cleavages in budding yeast reveal templated insertions and strand-specific insertion/deletion profiles. Proceedings of the National Academy of Sciences 115, E2040-E2047 (2018).

11. Zhou, H., Liu, B., Weeks, D. P., Spalding, M. H. \& Yang, B. Large chromosomal deletions and heritable small genetic changes induced by CRISPR/Cas9 in rice. Nucleic Acids Res. 42, 10903-10914 (2014).

12. Anzalone, A. V., Koblan, L. W. \& Liu, D. R. Genome editing with CRISPR-Cas nucleases, base editors, transposases and prime editors. Nat. Biotechnol. 38, 824-844 (2020).

13. Toal, T. W., et al. Indel group in genomes (IGG) molecular genetic markers. Plant Physiology (2016).

14. Doyle, J. J. \& Doyle, J. L. Isolation ofplant DNA from fresh tissue. Focus 12, 39-40 (1990).

15. Fauser, F., Schiml, S. \& Puchta, H. Both CRISPR/Cas-based nucleases and nickases can be used efficiently for genome engineering in Arabidopsis thaliana. Plant J. 79, 348-359 (2014).

16. Earley, K. W. et al. Gateway-compatible vectors for plant functional genomics and proteomics. The Plant Journal vol. 45 616-629 (2006). 
bioRxiv preprint doi: https://doi.org/10.1101/2021.07.16.452406; this version posted July 16, 2021. The copyright holder for this preprint (which

was not certified by peer review) is the author/funder, who has granted bioRxiv a license to display the preprint in perpetuity. It is made available under aCC-BY-NC-ND 4.0 International license.

17. Weijers, D. et al. An Arabidopsis Minute-like phenotype caused by a semi-dominant mutation in a RIBOSOMAL PROTEIN S5 gene. Development 128, 4289-4299 (2001). 
A

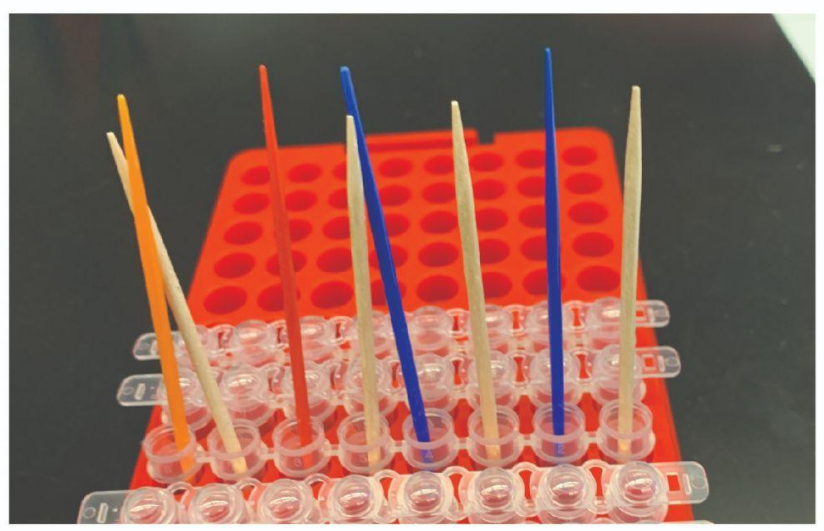

B
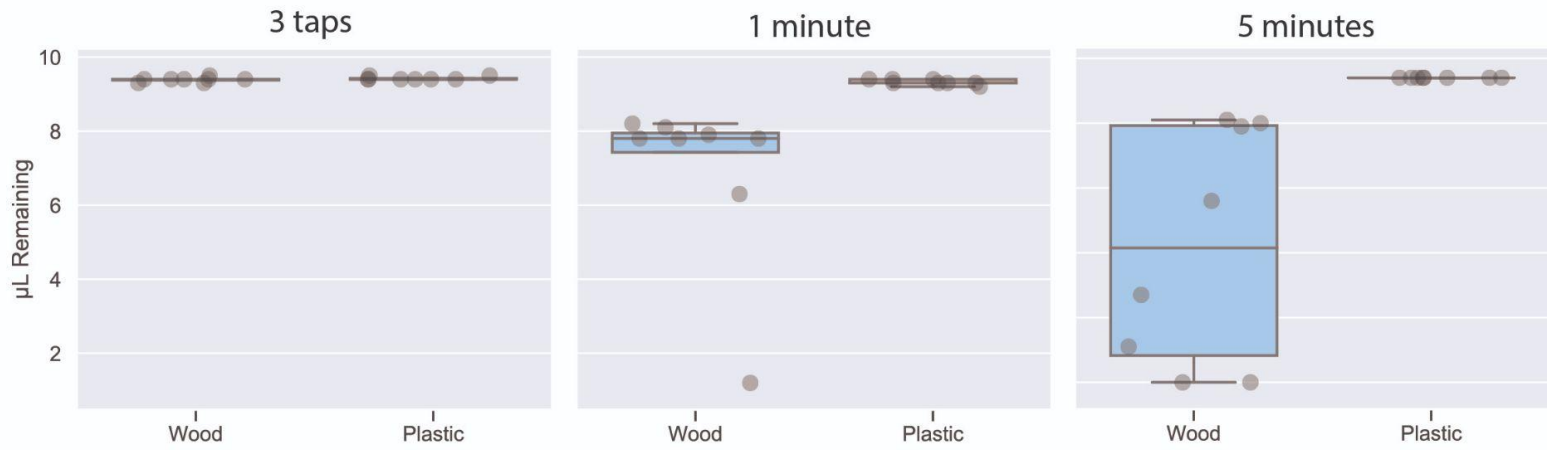

C

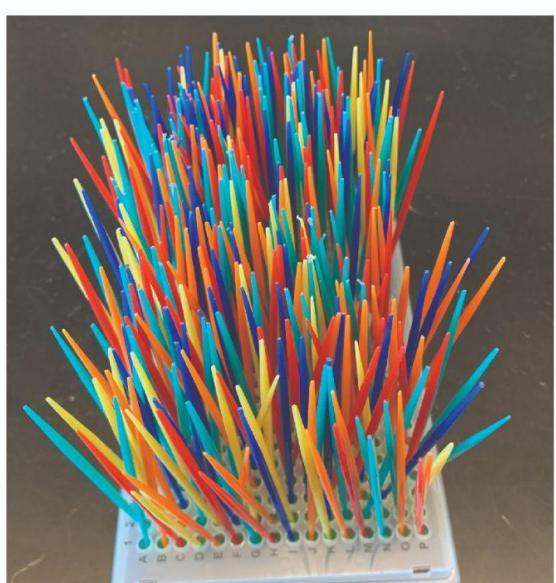

D

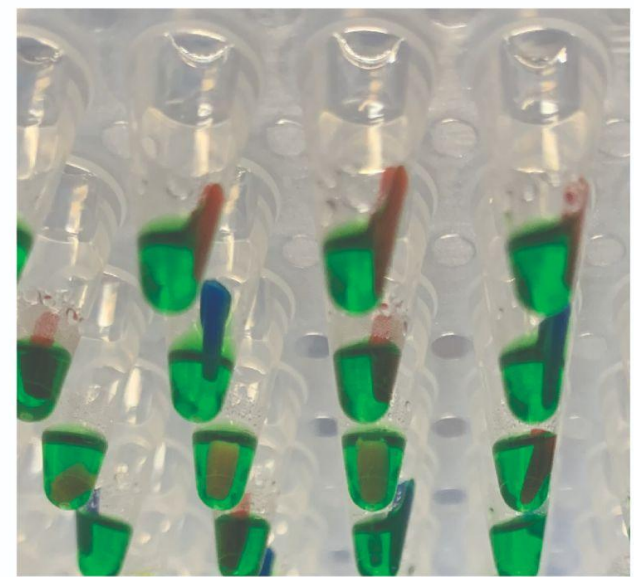

Supp. Fig. 1. Toothpicks for Direct PCR. A. Alternating wooden and plastic toothpicks placed into $10 \mu \mathrm{L}$ of PCR reagents. B. Liquid remaining after: 1) Immediately tapping the tip on the bottom of the tube 3 times; 2) Sitting for 3 minutes then removing the toothpicks; 3 ) Sitting for 5 minutes then removing the toothpicks. C. Plate of 384 plastic toothpicks that were each poked into a leaf, then placed into $10 \mu \mathrm{L}$ of PCR reagents. $D$. Testing cutting the tip of pipette tips, dropping them into $10 \mu \mathrm{L}$ of PCR reagents where they stay. The plastic toothpicks were too difficult to cut. 


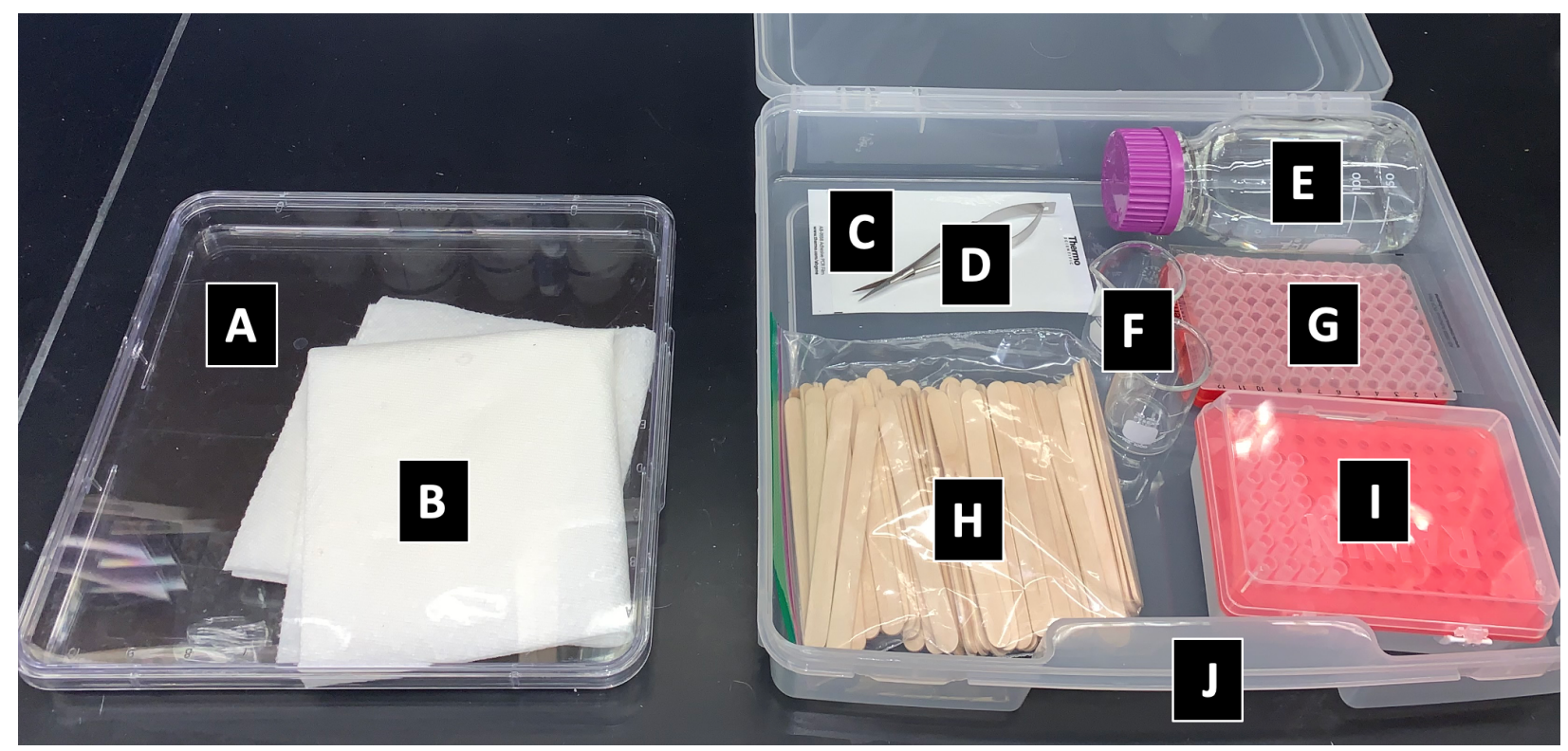

Supp. Fig. 2. Example kit for CutTip PCR. A. Clean tray. B. Paper towels. C. PCR sealing tape or caps. D. Scissors. E. Clean water. F. Two beakers.

G. Sealed PCR tubes containing all liquid reagents (not stored with kit). H. Popsicle sticks (flat wooden toothpicks also work). I. p20 pipette tips. J. Container for kit. 
A

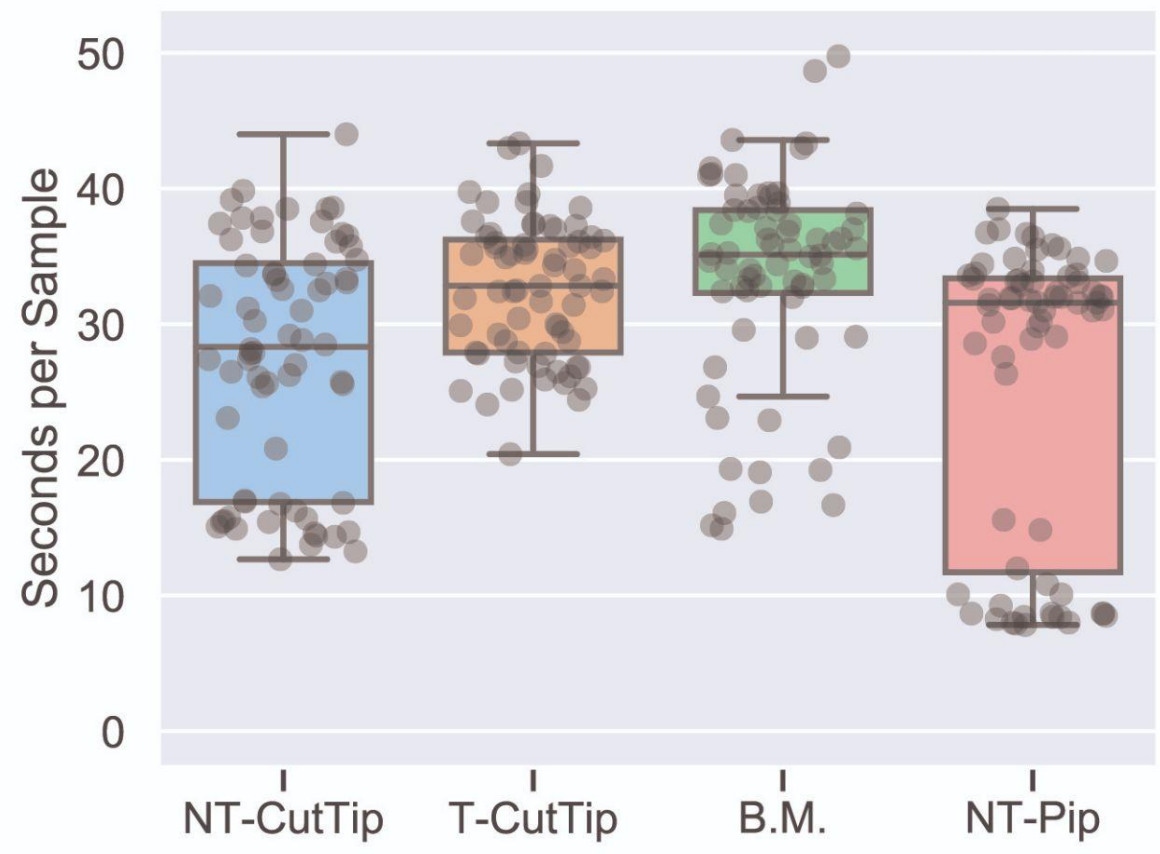

B

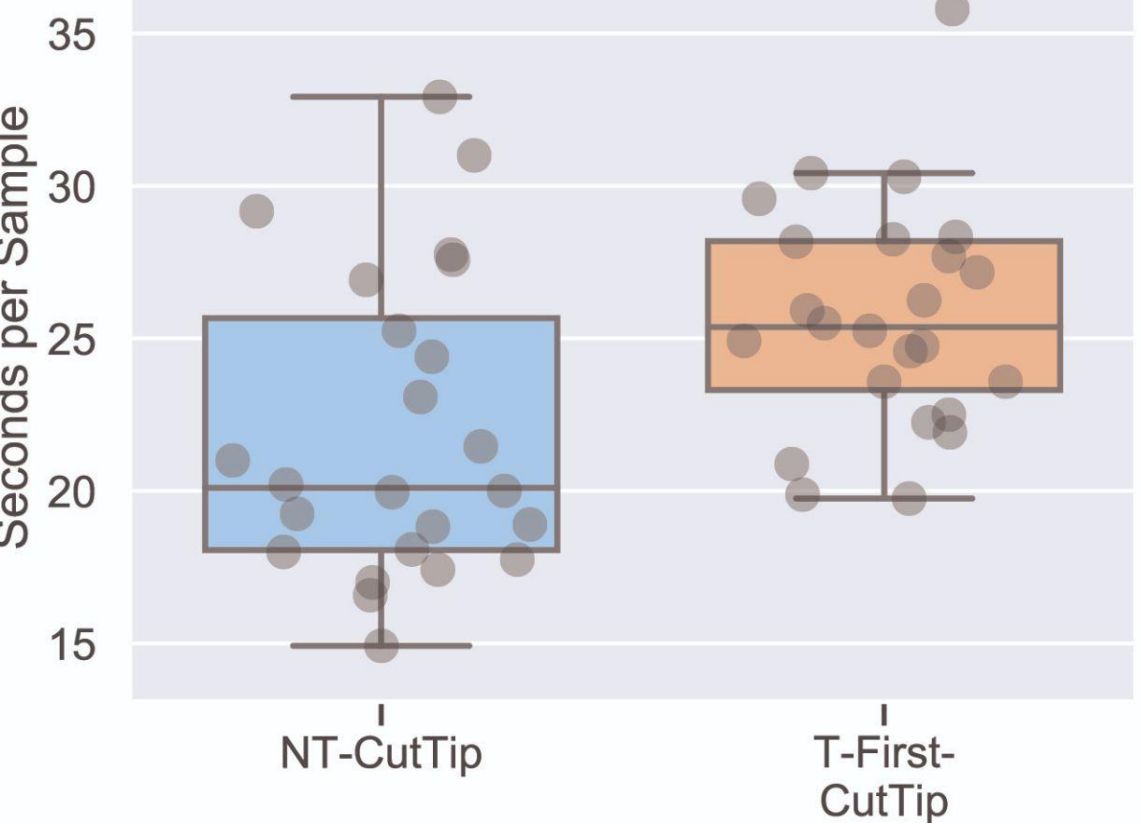

Supp. Fig. 3. Time to prepare a single sample, measured as the average number of seconds between 2 pokes in a series of 12 pokes. A. Comparison of 4 Direct PCR methods. Bimodal distributions can be explained by different technicians carrying out the procedure at different speeds, most obviously seen with NT-Pip. B. Comparison of 2 Direct PCR methods. 
A

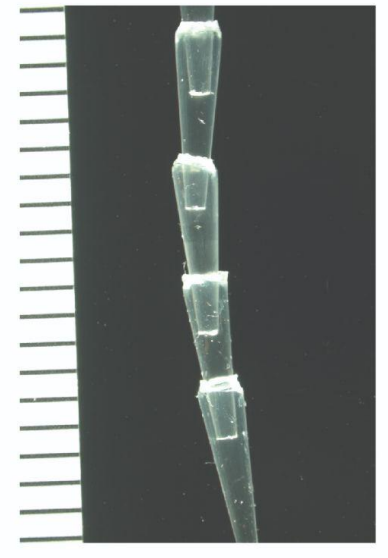

B

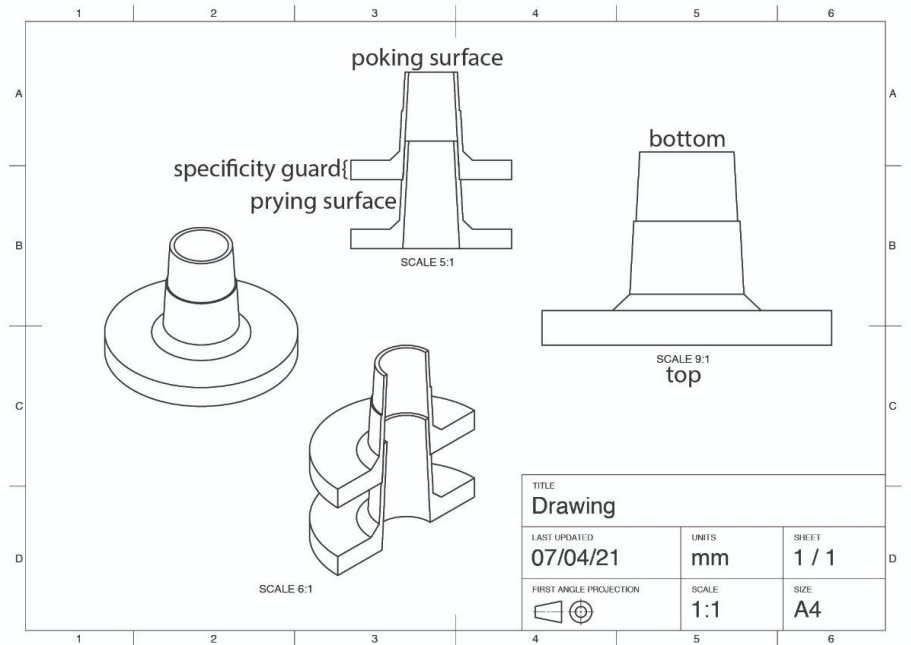

C

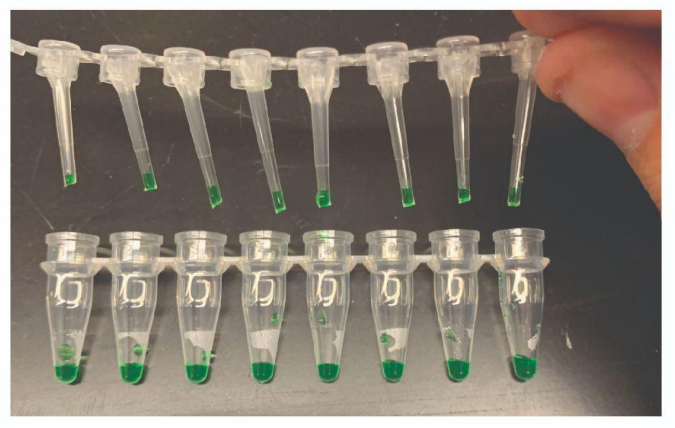

D

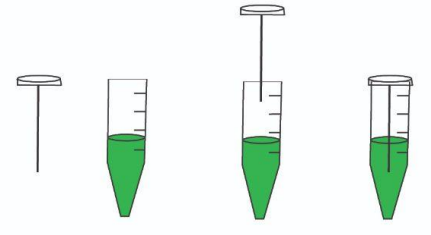

E

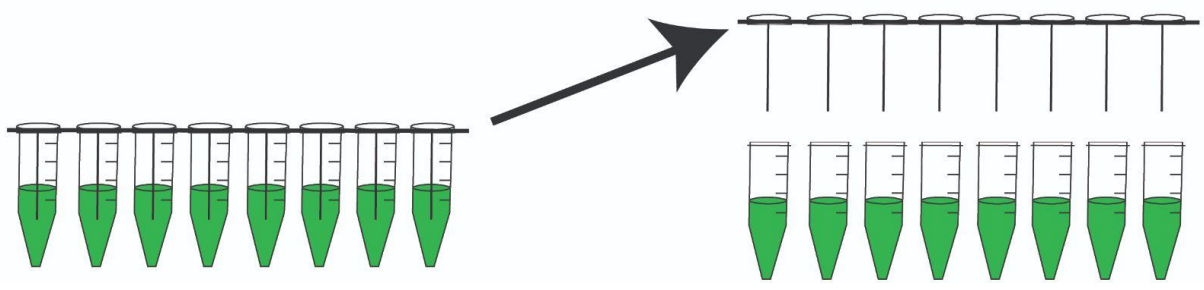

Supp. Fig. 4. Design ideas of specialized tools for Direct PCR. A-B. PryTip. A. Prototype with pipette tips. The linked tips can be held as one unit, with the bottom tip to be poked into tissue. The bottom tip is then dropped into the PCR reagents. (Scale $1 \mathrm{~mm}$.) B. Diagram of an improved version. After poking, the bottom poking tip is pried off and dropped into the PCR tube. The specificity guard ensures that DNA from the poke does not contaminate surfaces above the specificity guard. An optional hole in the center can facilitate pipetting the liquid out of the reaction tube. C-E. TopTip. C. Prototype with pipette tips. D. Diagram of an improved version. After a poke, the poking top is individually sealed onto the tube. E. After reaction, all poking tops can be simultaneously removed, such as by an adaptor or tape. 
bioRxiv preprint doi: https://doi.org/10.1101/2021.07.16.452406; this version posted July 16, 2021. The copyright holder for this preprint (which was not certified by peer review) is the author/funder, who has granted bioRxiv a license to display the preprint in perpetuity. It is made available under aCC-BY-NC-ND 4.0 International license.

\begin{tabular}{|c|c|c|c|c|c|c|c|c|c|c|c|c|c|c|c|}
\hline PCR Date & Method & $\begin{array}{l}\text { FPrimer } \\
\text { Name }\end{array}$ & F Primer Sequence & $\begin{array}{l}\text { RPrimer } \\
\text { Name }\end{array}$ & R Primer Sequence & $\begin{array}{c}\# \\
\text { cycles }\end{array}$ & $\begin{array}{l}\text { annealing } \\
\text { temp. }\end{array}$ & $\begin{array}{l}\text { elongation } \\
\text { seconds }\end{array}$ & \#FP & \#FN & \#TP & \#TN & Sensitivity & Specificity & Accuracy \\
\hline $05 / 25 / 2021$ & NT-Cut Tip & IGG-25-F & TGAATAGATCCACAAACTCGAAGATGG & IGG-25-R & GGATTTCAGTGATTAATATGATAGAGTCATC & 33 & 50 & 50 & 0 & 0 & 12 & 12 & 1.000 & 1.000 & 1.000 \\
\hline 05/25/2021 & T-First Cut Tip & IGG-25-F & TGAATAGATCCACAAACTCGAAGATGG & IGG-25-R & GGATTTCAGTGATTAATATGATAGAGTCATC & 33 & 50 & 50 & 0 & 0 & 12 & 12 & 1.000 & 1.000 & 1.000 \\
\hline $05 / 25 / 2021$ & NT-Cut Tip & Lec1-42-F & CCAAAGGATATTTCCGCTTCCATAGC & Lec1-43-R & GGAAATGCTACCTAGGAAAAGGACAC & 33 & 55 & 30 & 0 & 0 & 12 & 12 & 1.000 & 1.000 & 1.000 \\
\hline 05/25/2021 & T-First Cut Tip & Lec1-42-F & CCAAAGGATATTTCCGCTTCCATAGC & Lec1-43-R & GGAAATGCTACCTAGGAAAAGGACAC & 33 & 55 & 30 & 0 & 0 & 12 & 12 & 1.000 & 1.000 & 1.000 \\
\hline $05 / 14 / 2021$ & NT-Gut Tip & IGG-17-F & GAGCCAATAGAACCCATTTGACTGAG & IGG-17-R & CTTTTTGGCCTATGCCTTCCAAGTTC & 33 & 55 & 36 & 0 & 0 & 12 & 12 & 1.000 & 1.000 & 1.000 \\
\hline $05 / 14 / 2021$ & T-First Cut Tip & IGG-17-F & GAGCCAATAGAACCCATTTGACTGAG & IGG-17-R & CTTTTTCGCCTATGCCTTCCAAGTTC & 33 & 55 & 36 & 1 & 0 & 12 & 11 & 1.000 & 0.917 & 0.958 \\
\hline $05 / 14 / 2021$ & NT-Cut Tip & IGG-40b-F & ACCAAGGGAAATAGTCAGCCGAGAGTC & IGG-40b-R & AGTGAGATAAGGAGCGAGGAATTTACCTG & 33 & 57 & 36 & 0 & 1 & 11 & 12 & 0.917 & 1.000 & 0.958 \\
\hline $05 / 14 / 2021$ & T-First Cut Tip & $1 G G-40 b-F$ & ACCAAGGGAAATAGTCAGCCGAGAGTC & $1 G G-40 b-R$ & AGTGAGATAAGGAGCGAGGAATTTACCTG & 33 & 57 & 36 & 0 & 0 & 12 & 12 & 1.000 & 1.000 & 1.000 \\
\hline $05 / 12 / 2021$ & NT-Cut Tip & IGG-2-F & AAACTGTTACGAGCAATGTATATGAATCG & IGG-3-R & AAGAGACGGACATGAAACTTACGTTG & 33 & 53 & 30 & 0 & 0 & 12 & 12 & 1.000 & 1.000 & 1.000 \\
\hline $05 / 12 / 2021$ & T-First Cut Tip & IGG-2-F & AAACTGTTACGAGCAATGTATATGAATCG & IGG-3-R & AAGAGACGGACATGAAACTTACGTTG & 33 & 53 & 30 & 0 & 0 & 12 & 12 & 1.000 & 1.000 & 1.000 \\
\hline $05 / 12 / 2021$ & NT-Cut Tip & IGG-43b-F & GTTTAAGGAATTTGACATTAATTCTAGCCAGAG & IGG-43-C-R & AAGCCTTACACGCTAATAGATTATCAAATCTG & 33 & 52 & 36 & 2 & 0 & 12 & 10 & 1.000 & 0.833 & 0.917 \\
\hline 05/12/2021 & T-First Cut Tip & IGG-43b-F & GTTTAAGGAATTTGACATTAATTCTAGGCAGAG & IGG-43-C-R & AAGCGTTACACGCTAATAGATTATCAAATCTG & 33 & 52 & 36 & 0 & 0 & 12 & 12 & 1.000 & 1.000 & 1.000 \\
\hline $05 / 11 / 2021$ & NT-Cut Tip & IGG-42-F & ATGTGGAATTCTGACTAATGTCTAATGTC & IGG-42-R & GTTTTAGGCAATCTAATGGAAATCTCAATC & 33 & 51 & 36 & 0 & 0 & 12 & 12 & 1.000 & 1.000 & 1.000 \\
\hline $05 / 11 / 2021$ & T-First Cut Tip & IGG-42-F & ATGTGGAATTCTGACTAATGTCTAATGTC & IGG-42-R & GTTTAGGCAATCTAATGGAAATCTCAATC & 33 & 51 & 36 & 0 & 0 & 12 & 12 & 1.000 & 1.000 & 1.000 \\
\hline $05 / 11 / 2021$ & NT-Cut Tip & IGG-23-F & GATTTGAAGTTGGAATTTCTTCTGTTCTG & IGG-23-R & TITTGAGACCTATTTCGGTATCCTGAG & 33 & 51 & 36 & 1 & 0 & 12 & 11 & 1.000 & 0.917 & 0.958 \\
\hline $05 / 11 / 2021$ & T-First Cut Tip & IGG-23-F & GATTTGAAGTTGGAATTTCTTCTGTTCTG & IGG-23-R & TITTGAGACCTATTTCCGTATCCTGAG & 33 & 51 & 36 & 0 & 0 & 12 & 12 & & 1.000 & 1.000 \\
\hline $05 / 06 / 2021$ & T-Cut Tip & $67-\mathrm{C}-\mathrm{F}$ & GTCATTGTATACACATTAACCTAACAAGC & $67-d-R$ & CTTTAAGGAATGGACTTAGCGTTGAC & 33 & 55 & 33 & N/A & 0 & 10 & N/A & 1.000 & $N / A$ & N/A \\
\hline 05/06/2021 & NT-Cut Tip & $67-\mathrm{C}-\mathrm{F}$ & GTCATTGTATACACATTAACCTAACAAGC & $67-d-R$ & CTTTAAGGAATGGACTTAGCGTTGAC & 33 & 55 & 33 & N/A & 0 & 10 & N/A & 1.000 & $N / A$ & N/A \\
\hline $05 / 06 / 2021$ & Berthomieu-Meyer & 67-C-F & GTCATTGTATACACATTAACCTAACAAGC & 67-d-R & СTTTAAGGAATGGACTTAGCGTTGAC & 33 & 55 & 33 & N/A & 0 & 10 & N/A & & $N / A$ & N/A \\
\hline $05 / 06 / 2021$ & NT-Pip & $67-\mathrm{C}-\mathrm{F}$ & GTCATTGTATACACATTAACCTAACAAGC & $67-d-R$ & CTTTAAGGAATGGACTTAGCGTTGAC & 33 & 55 & 33 & N/A & 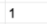 & 9 & N/A & & N/A & N/A \\
\hline $05 / 06 / 2021$ & T-Cut Tip & $\mathrm{CH} 1-12-\mathrm{F}$ & CTGGCAAATCCCTCTTCATCATCATG & $\mathrm{CH} 1-30-\mathrm{R}$ & TTTGACACTGATTACAGAGTTTGAAGCC & 33 & 54 & 40 & N/A & 0 & 10 & N/A & & N/A & N/A \\
\hline $05 / 06 / 2021$ & NT-Cut Tip & $\mathrm{CH} 1-12-\mathrm{F}$ & CTGGCAAATCCCTCTTCATCATCATG & $\mathrm{CH} 1-30-\mathrm{R}$ & TITGACACTGATTACAGAGTTTGAAGCC & 33 & 54 & 40 & N/A & 0 & 10 & N/A & 1.000 & N/A & N/A \\
\hline $05 / 06 / 2021$ & Berthomieu-Meyer & CH1-12-F & CTGGCAAATCCCTCTTCATCATCATG & $\mathrm{CH} 1-30-\mathrm{R}$ & TTTGACACTGATTACAGAGTTTGAAGCC & 33 & 54 & 40 & N/A & 0 & 10 & N/A & & N/A & N/A \\
\hline $05 / 06 / 2021$ & NT-Pip & $\mathrm{CH} 1-12-\mathrm{F}$ & & & TTTG & 33 & 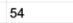 & 40 & & & 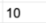 & & & & N/A \\
\hline $05 / 04 / 2021$ & T-Cut Tip & ARR10-4-F & СTTCAATTTCTTGCTCCATAGTCATCG & ARR10-3-R & CACTGAATTTTCTCAGAGATTCTCCTC & 33 & 52 & 36 & N/A & 0 & 10 & N/A & 1.000 & N/A & N/A \\
\hline $05 / 04 / 2021$ & NT-Cut Tip & ARR10-4-F & СTTCAATTTCTTGCTCCATAGTCATCG & ARR10-3-R & CACTGAATTTTCTCAGAGATTCTCCTC & 33 & 52 & 36 & N/A & 0 & 10 & N/A & 1.000 & N/A & N/A \\
\hline
\end{tabular}

Supp. Table 1: PCR methods, parameters and results using Arabidopsis. (Excerpt displayed here.)

\begin{tabular}{|c|c|c|c|c|c|}
\hline PCR date & Method & $\begin{array}{l}\text { F Primer } \\
\text { Name }\end{array}$ & F Primer Sequence & $\begin{array}{l}\text { R Primer } \\
\text { Name }\end{array}$ & r Sequence \\
\hline 1126 & NT-Pip & Kita-2-F & GTCACAGACCGGTCAGATCGTGGGTTAG & Kita-2-R & GCTGATGACATGACCAGTGTC \\
\hline 1126 & NT-Cut Tip & Kita-2-F & GTCACAGACCGGTCAGATCGTGGGTTAG & Kita-2-R & GGCTGTCTGCTGATGACATGACCAGTGTC \\
\hline 11262020 & NT-Pip & Kita-3-F & CATCCACAATGTATGCCATAAGGAGGGTC & Kita-3-R & TTCCCCTTTCTATGTCGAGGCTTCCATTC \\
\hline 11262020 & NT-Cut Tip & Kita-3-F & CATCCACAATGTATGCCATAAGGAGGGTC & Kita-3-R & TTCCCCTTTCTATGTCGAGGCTTCCATTC \\
\hline 1282020 & NT-Pip & Kita-4-F & AGTATCGGAGTTTCAGCCGATCTTATCTG & Kita-4-R & AGTGATTGGGATAGATCGGTCATCATGC \\
\hline 0 & NT-Cut Tip & Kita-4-F & AGTATCGGAGTTTCAGCCGATCTTATCTG & Kita-4-R & AGTGATTGGGATAGATCGGTCATCATGC \\
\hline 1282020 & NT-Pip & Kita-5-F & GGACCATTAGTGCAACAGGATTAGGTAAC & Kita-5-R & GCAGCAAGGACTAGAGAATAGTTATCATAGCC \\
\hline 282020 & NT-Cut Tip & Kita-5-F & GGACCATTAGTGCAACAGGATTAGGTAAC & Kita-5-R & GCAGCAAGGACTAGAGAATAGTTATCATAGCC \\
\hline .1282020 & NT-Pip & Kita-6-F & CCCTATTTATTTCCTAAGGTCCTAATGGC & Kita-6-R & CGAATACGGATACAAACTCGGATAATGTTG \\
\hline 11282020 & NT-Cut Tip & Kita-6-F & СCCTATTTATTTCCTAAGGTCCTAATGGC & Kita-6-R & CGAATACGGATACAAACTCGGATAATGTTG \\
\hline 11282020 & NT-Pip & Kita-7-F & ACTCATGTCACTCCTCTGCCTTCTCGTC & Kita-7-R & GCAGTAGCCGTAGTAGATCGACACAGGTG \\
\hline $11282020 \mathrm{I}$ & NT-Cut Tip & Kita-7-F & АСTCATGTCACTCCTCTGCCTTCTCGTC & Kita-7-R & GCAGTAGCCGTAGTAGATCGACACAGGTG \\
\hline $12022020 \mathrm{I}$ & NT-Pip & Kita-8-F & GGGTCACAATCATGTTGCAACAATAGCTCG & Kita-8-R & CAAACGACGCTTTGGACCGGGATGATAC \\
\hline 120 & NT-Cut Tip & Kita-8-F & GGGTCACAATCATGTTGCAACAATAGCTCG & Kita-8-R & CAAACGACGCTITGGACCGGGATGATAC \\
\hline & & & & $a-9-5$ & \\
\hline & & & AGGAAACAA & & TACST \\
\hline
\end{tabular}

\begin{tabular}{|c|c|c|c|c|c|c|c|c|c|}
\hline $\begin{array}{c}\# \\
\text { cycles }\end{array}$ & $\begin{array}{c}\text { annealing } \\
\text { temp. }\end{array}$ & $\begin{array}{l}\text { elongation } \\
\text { cycles }\end{array}$ & \#FN & \#TP & \#FP & $\# \mathrm{TN}$ & Sensitivity & $\begin{array}{l}\text { Specificity } \\
\text { Index }\end{array}$ & $\begin{array}{l}\text { Accuracy } \\
\text { Index }\end{array}$ \\
\hline 33 & 55 & 45 & 0 & 12 & 0 & 12 & 1.00 & 1.00 & 1.00 \\
\hline 33 & 55 & 45 & 0 & 12 & 0 & 12 & 1.00 & 1.00 & 1.00 \\
\hline 33 & 55 & 45 & 1 & 11 & 0 & 12 & 0.92 & 1.00 & 0.96 \\
\hline 33 & 55 & 45 & 0 & 12 & 0 & 12 & 1.00 & 1.00 & 1.00 \\
\hline 33 & 55 & 45 & 0 & 12 & 0 & 12 & 1.00 & 1.00 & 1.00 \\
\hline 33 & 55 & 45 & 0 & 12 & 0 & 12 & 1.00 & 1.00 & 1.00 \\
\hline 33 & 55 & 45 & 6 & 6 & 0 & 12 & 0.50 & 1.00 & 0.75 \\
\hline 33 & 55 & 45 & 0 & 12 & 0 & 12 & 1.00 & 1.00 & 1.00 \\
\hline 33 & 55 & 45 & 10 & 2 & 0 & 12 & 0.17 & 1.00 & 0.58 \\
\hline 33 & 55 & 45 & 2 & 10 & 0 & 12 & 0.83 & 1.00 & 0.92 \\
\hline 33 & 55 & 45 & 3 & 9 & 0 & 12 & 0.75 & 1.00 & 0.88 \\
\hline 33 & 55 & 45 & 0 & 12 & 0 & 12 & 1.00 & 1.00 & 1.00 \\
\hline 33 & 55 & 45 & 5 & 7 & 0 & 12 & 0.58 & 1.00 & 0.79 \\
\hline 33 & 55 & 45 & 1 & 11 & 0 & 12 & 0.92 & 1.00 & 0.96 \\
\hline 33 & 55 & 55 & 1 & 11 & 0 & 12 & 0.92 & 1.00 & 0.96 \\
\hline
\end{tabular}

Supp. Table 2: PCR methods, parameters and results using rice. 


\begin{tabular}{|c|c|c|}
\hline Problem & Possible Reason & Suggested Solution \\
\hline \multirow{6}{*}{$\begin{array}{l}\text { False } \\
\text { Positives }\end{array}$} & $\begin{array}{l}\text { DNA from previous } \\
\text { samples reaching } \\
\text { above cut. }\end{array}$ & $\begin{array}{l}\text { Cut 2-3 mm. pieces. When poking, don't let tissue touch } 1 \\
\mathrm{~mm} \text {. above bottom of tip. If tissue touches } 1 \mathrm{~mm} \text {. above } \\
\text { bottom of tip, discard pipette tip. }\end{array}$ \\
\hline & $\begin{array}{l}\text { DNA from previous } \\
\text { sample on scissors. }\end{array}$ & $\begin{array}{l}\text { Use wet paper towel to wipe the entire scissor cutting surface. } \\
\text { Keep paper towels on a non-contaminated surface. Use } 2 \\
\text { beakers of cleaning water for dipping scissors as described. }\end{array}$ \\
\hline & $\begin{array}{l}\text { Other contaminated } \\
\text { tools or reagents. }\end{array}$ & $\begin{array}{l}\text { Use new reagents and cleaning water. Use filtered pipette tips } \\
\text { when pipetting reagents into PCR plate (filter not necessary } \\
\text { for poking for CutTip). Regularly clean all tools and surfaces. } \\
\text { Use new popsicle stick or single-use flat wooden toothpicks. }\end{array}$ \\
\hline & $\begin{array}{l}\text { Non-specific } \\
\text { primers. }\end{array}$ & Use $25-32$ bp primers. Increase annealing temperature. \\
\hline & $\begin{array}{l}\text { CutTip hopped into } \\
\text { wrong well. }\end{array}$ & $\begin{array}{l}\text { Angle the tip into the well as seen in Fig. } 3 \mathrm{C} \text { and Supp. Movie } \\
\text { Don't cut above top of well. Iterative cuts are heavier, helping } \\
\text { drop into correct well. }\end{array}$ \\
\hline & Cut into wrong well. & $\begin{array}{l}\text { Put informative stickers over plate near where cutting. Can } \\
\text { validate by using a microscope to count one tip per well. }\end{array}$ \\
\hline \multirow{8}{*}{$\begin{array}{l}\text { False } \\
\text { Negatives }\end{array}$} & Tissue too large. & Use NT-CutTip, B.M. or T-First-CutTip. \\
\hline & $\begin{array}{l}\text { No template } \\
\text { contacting PCR } \\
\text { solution. }\end{array}$ & $\begin{array}{l}\text { When poking, swivel the tip to get cell smear all around. If } \\
\text { using visible tissue, make sure the tissue is not stuck in the } \\
\text { pipette tip nor on the tube wall. }\end{array}$ \\
\hline & Very faint band. & Increase PCR cycles. \\
\hline & $\begin{array}{l}\text { Several hours of } \\
\text { sampling at room } \\
\text { temperature. }\end{array}$ & If $>3$ hours of PCR preparation, use ice. \\
\hline & $\begin{array}{l}\text { Mismatches } \\
\text { between primer and } \\
\text { target. }\end{array}$ & $\begin{array}{l}\text { Design primers based on correct DNA sequences. Design } \\
\text { primers based on Sanger sequencing the primer region using } \\
\text { the plant of interest. }\end{array}$ \\
\hline & $\begin{array}{l}\text { Cut tip hopped into } \\
\text { wrong well. }\end{array}$ & $\begin{array}{l}\text { Angle the tip into the well as seen in Fig. } 3 \text { C and Supp. } \\
\text { Movie. Don't cut above top of well. Iterative cuts are heavier, } \\
\text { helping drop into correct well. }\end{array}$ \\
\hline & Cut into wrong well. & $\begin{array}{l}\text { Put stickers on plate sealing tape near where cutting. Can } \\
\text { validate using a microscope to count one tip per well. }\end{array}$ \\
\hline & $\begin{array}{l}\text { Amplicon size too } \\
\text { small or large. }\end{array}$ & Aim for $160-600$ bp amplicons. \\
\hline
\end{tabular}

Supp. Table 3: Troubleshooting Guide 
Supp. Movie 1: Protocol of NT-CutTip. Can be viewed at https://youtu.be/F-KiL9epodM

Supp. Movie 1 description:

0:00-0:05 Text: "Supplementary Movie 1: Protocol of NT-CutTip. Please cite: Lynagh et al. 2021. Accurate Direct PCR with Arabidopsis and rice"

0:06-0:13 Text: "Suggested Materials: tray; paper towels; clean water; PCR plate sealing tape or caps; two beakers; wooden flat toothpicks or popsicle sticks; $20 \mu \mathrm{L}$ pipette tips such as Rainin; PCR reagents; PCR plate; squeeze scissors; thermocycler" 0:14-0:38 Step 1: Mix PCR reagents and add $10 \mu \mathrm{L}$ to each PCR reaction well. 0:39-0:44 Step 2: Hold a flat wooden toothpick or popsicle stick under the leaf of interest.

0:45-0:52 Step 3: Press and twist the pipette tip with moderate force through the leaf and into the wood.

0:53-1:02 Step 4: Cut the tip of the tip over the well so that it falls into the PCR reagents.

1:03-1:16 Step 5: Dip scissors in clean water beaker \#1. Wipe scissor blades with a wet towel. Dip scissors in clean water beaker \#2. Wipe dry.

1:17-2:09 Step 6: Repeat Steps 2-5 until all samples are completed.

2:10-2:27 Step 7: Seal all wells.

2:28-2:39 Step 8: Vortex the PCR plate for 5 seconds. Centrifuge the PCR plate for up to 2 minutes in case any cut tips are above the liquid.

2:40-2:53 Step 9: Put in thermocycler and begin the PCR. Typically 33-40 cycles works well.

2:54-3:02 Text: "End. Please cite Lynagh et al. 2021. Accurate Direct PCR with Arabidopsis and rice" 